\title{
Índice general de Shupibui: Revista Latinoamericana de Actualidad y Análisis (1976-1990)
}

\section{General index of Shupibui: Revista Latinoamericana de Actualidad y Análisis (1976-1990)}

\section{Jorge Carranza Orbegoso ${ }^{1}$}

A los que hicieron posible el Centro de Estudios Teológicos de la Amazonia (CETA)

\section{Resumen}

El índice registra el contenido de 52 números de Shupihui: Revista Latinoamericana de Actualidad y Análisis desde el año de su creación en 1976 hasta su última edición en 1990. El índice general presenta cronológicamente el contenido de cada número en orden ascendente desde el primer hasta el último número. Los artículos mantienen el orden consecutivo y la correspondiente paginación.

Palabras clave: Shupihui, Centro de Estudios Teológicos de la Amazonía (CETA), índice cronológico, revistas peruanas, Perú, Amazonía.

1 Arqueólogo y miembro del Grupo de Estudio Amazonía hacia el Bicentenario del Instituto Riva-Agüero de la Pontificia Universidad Católica del Perú. Correspondencia (Corresponding author): j.carranzaorbegoso@gmail.com; Código ORCID: 0000-0003-1635-3778 
Índice general de Shupihui: Revista Latinoamericana de Actualidad y Análisis (19761990)

\section{Abstract}

The index records the content of 52 issues of Shupibui: Revista Latinoamericana de Actualidad y Análisis from the year of its creation in 1976 to its last edition in 1990. The general index presents chronologically the contents of each issue in ascending order from the first to the last issue. The articles maintain the consecutive order and the corresponding pagination.

Key words: Shupihui: Centro de Estudios Teológicos de la Amazonía (CETA), chronological index, Peruvian journals, Peru, Amazonia.

\section{Introducción}

Shupihui: Revista Latinoamericana de Actualidad y Análisis apareció en 1976 como un boletín de la Coordinación Pastoral de la Selva (Perú), dirigido a los agentes pastorales con temas sobre actualidad religiosa latinoamericana. En 1978, la Coordinación Pastoral de la Selva (Perú) tuvo la colaboración del Centro Amazónico de Antropología y Aplicación Práctica (CAAAP) para la edición conjunta con la finalidad de ampliar los contenidos y la periodicidad. La colaboración de ambas instituciones se mantuvo durante los siguientes nueve números y luego el Centro de Estudios Teológicos de la Amazonía (CETA) asumió la edición general como una revista de actua-

402 lidad y análisis de la problemática de América Latina.

En total, Shupihui: Revista Latinoamericana de Actualidad y Análisis ha publicado 52 números en 14 años, desde 1976 hasta 1990 (Tabla 1, Figura 1 y 2) ${ }^{2}$.

2 La colección de Shupihui: Revista Latinoamericana de Actualidad y Análisis se encuentra en la ciudad de Iquitos (Maynas, Loreto) en la Biblioteca 


\section{Tabla 1. Ediciones de Shupibui: Revista Latinoamericana de Actualidad y Análisis}

\begin{tabular}{|c|c|c|c|c|}
\hline Año & Volumen & $\mathrm{N}^{\circ}$ & Meses & Tema \\
\hline \multirow{3}{*}{1976} & \multirow{3}{*}{ I } & 1 & Abril-junio & La religiosidad popular, Tema: A \\
\hline & & 2 & Julio-setiembre & La religiosidad popular aplicada, Tema: B \\
\hline & & 3 & $\begin{array}{l}\text { Octubre- } \\
\text { diciembre }\end{array}$ & Comunidades cristianas rurales \\
\hline \multirow{2}{*}{1977} & \multirow{2}{*}{ II } & 4 & Enero-junio & $\begin{array}{l}\text { Comunidades cristianas en la América La- } \\
\text { tina: Experiencias y reflexiones }\end{array}$ \\
\hline & & 5 & Julio-diciembre & $\begin{array}{l}\text { Pastoral indigenista en los países amazó- } \\
\text { nicos }\end{array}$ \\
\hline \multirow{3}{*}{1978} & \multirow{3}{*}{ III } & 6 & Enero-marzo & Sectas cristianas en la selva del Perú \\
\hline & & 7 & Abril-junio & $\begin{array}{l}\text { Partidos políticos en el proceso hacia la } \\
\text { constituyente }\end{array}$ \\
\hline & & 8 & Julio-diciembre & Grupos indígenas hoy \\
\hline \multirow{4}{*}{1979} & \multirow{4}{*}{ IV } & 9 & Enero-marzo & Puebla, culturas e indigenismo \\
\hline & & 10 & Abril-junio & Vida consagrada en América Latina \\
\hline & & 11 & Julio-setiembre & Los nuevos caminos de la medicina \\
\hline & & 12 & $\begin{array}{l}\text { Octubre- } \\
\text { diciembre }\end{array}$ & $\begin{array}{l}\text { Movimientos populares en el Perú y en } \\
\text { América Latina }\end{array}$ \\
\hline
\end{tabular}

Amazónica del Vicariato Apostólico de Iquitos (antes adscrita al CETA) y en la Biblioteca Pública Municipal "Joaquín García Sánchez" de la Municipalidad Provincial de Maynas (Sala Amazonía). En Lima, se encuentra en la Biblioteca Nacional del Perú (Sala Hemeroteca Nacional), en el Centro Amazónico de Antropología y Aplicación Práctica (Centro de Documentación), en el Instituto Francés de Estudios Andinos (Biblioteca), en la Pontificia Universidad Católica del Perú (Biblioteca Central "Luis Jaime Cisneros", Hemeroteca Central, y en la Biblioteca del Instituto Riva-Agüero) y en el Club Loreto (Biblioteca Emilia Barcia Boniffatti). El número seis de la serie se puede consultar en la Biblioteca del Centro Bartolomé de las Casas (Cusco). 
Índice general de Shupihui: Revista Latinoamericana de Actualidad y Análisis (19761990)

\begin{tabular}{|c|c|c|c|c|c|}
\hline & Año & Volumen & $\mathrm{N}^{\circ}$ & Meses & Tema \\
\hline & \multirow{4}{*}{1980} & \multirow{4}{*}{$\mathrm{V}$} & 13 & Enero-marzo & $\begin{array}{l}\text { La danza de las ofertas políticas a la Ce- } \\
\text { nicienta }\end{array}$ \\
\hline & & & 14 & Abril-junio & Problemas y esperanzas de la familia \\
\hline & & & 15 & Julio-setiembre & Hacia la conquista de la Amazonía (I) \\
\hline & & & 16 & $\begin{array}{l}\text { Octubre- } \\
\text { diciembre }\end{array}$ & Hacia la conquista de la Amazonía (II) \\
\hline & \multirow{4}{*}{1981} & \multirow{4}{*}{$\mathrm{VI}$} & 17 & Enero-marzo & Iglesia e indigenismo en América Latina \\
\hline & & & 18 & Abril-junio & La Amazonía en el cine \\
\hline & & & 19 & Julio-setiembre & La literatura de la Amazonía peruana \\
\hline & & & 20 & $\begin{array}{l}\text { Octubre- } \\
\text { diciembre }\end{array}$ & $\begin{array}{l}\text { II Coloquio sobre la Nueva Conquista de } \\
\text { la Selva }\end{array}$ \\
\hline & \multirow{3}{*}{1982} & \multirow{3}{*}{ VII } & 21 & Enero-marzo & $\begin{array}{l}\text { Petróleo y transnacionales; culturas indí- } \\
\text { genas y evangelización }\end{array}$ \\
\hline & & & 22 & Abril-junio & $\begin{array}{l}\text { El canon, garantía para la defensa de nues- } \\
\text { tras fronteras }\end{array}$ \\
\hline & & & $\begin{array}{l}23- \\
24 \\
\end{array}$ & Julio-diciembre & $\begin{array}{l}\text { Homenaje al Padre Jesús Víctor San Ro- } \\
\text { mán }\end{array}$ \\
\hline & \multirow{3}{*}{1983} & \multirow{3}{*}{ VIII } & $\begin{array}{l}25- \\
26\end{array}$ & Enero-junio & $\begin{array}{l}\text { Centroamérica, escenario de pretensiones } \\
\text { hegemónicas }\end{array}$ \\
\hline & & & 27 & Julio-setiembre & $\begin{array}{l}\text { Despertar de los pueblos indígenas en } \\
\text { América Latina }\end{array}$ \\
\hline & & & 28 & $\begin{array}{l}\text { Octubre- } \\
\text { diciembre }\end{array}$ & $\begin{array}{l}\text { III Coloquio sobre la Nueva Conquista de } \\
\text { la Selva }\end{array}$ \\
\hline \multirow{3}{*}{404} & \multirow{3}{*}{1984} & \multirow{3}{*}{ IX } & 29 & Enero-marzo & $\begin{array}{l}\text { Sondeo de las fuentes históricas para un } \\
\text { conocimiento objetivo del pasado de la } \\
\text { Amazonía }\end{array}$ \\
\hline & & & 30 & Abril-junio & $\begin{array}{l}\text { Bilingüismo y educación bilingüe en las } \\
\text { minorías indígenas amazónicas: fracasos y } \\
\text { expectativas }\end{array}$ \\
\hline & & & $\begin{array}{l}31- \\
32\end{array}$ & Julio-diciembre & $\begin{array}{l}\text { Teología de la liberación en la teología de } \\
\text { la misión: encuentro fecundo de dos co- } \\
\text { rrientes de Iglesia }\end{array}$ \\
\hline
\end{tabular}




\begin{tabular}{|c|c|c|c|c|}
\hline Año & Volumen & $\mathrm{N}^{\circ}$ & Meses & Tema \\
\hline \multirow{3}{*}{1985} & \multirow{3}{*}{$\mathrm{X}$} & 33 & Enero-marzo & $\begin{array}{l}\text { Discurso misionero de Juan Pablo II: el } \\
\text { viaje del Papa por América India }\end{array}$ \\
\hline & & 34 & Abril-junio & $\begin{array}{l}\text { El presente y el futuro de la Salud en la } \\
\text { Amazonía }\end{array}$ \\
\hline & & $\begin{array}{l}35- \\
36\end{array}$ & Julio-diciembre & $\begin{array}{l}\text { Situación actual de la Mujer en la Amazo- } \\
\text { nía y en el Perú }\end{array}$ \\
\hline \multirow{3}{*}{1986} & \multirow{3}{*}{ XI } & 37 & Enero-marzo & $\begin{array}{l}\text { Dinámica poblacional en la Amazonía del } \\
\text { Perú }\end{array}$ \\
\hline & & 38 & Abril-junio & Proyecto Monumenta Amazónica \\
\hline & & $\begin{array}{l}39- \\
40\end{array}$ & Julio-diciembre & Pueblos indígenas de América \\
\hline \multirow{2}{*}{1987} & \multirow{2}{*}{ XII } & 41 & Enero-marzo & $\begin{array}{l}\text { Cultura, cosmovisión y problemática indí- } \\
\text { genas en América Latina }\end{array}$ \\
\hline & & $\begin{array}{l}42- \\
44\end{array}$ & Abril-diciembre & $\begin{array}{l}\text { La región del Amazonas. Los políticos } \\
\text { amazónicos se pronuncian }\end{array}$ \\
\hline \multirow{2}{*}{1988} & \multirow{2}{*}{ XIII } & $\begin{array}{l}45- \\
46\end{array}$ & Enero-junio & La música en la Amazonía. 1. Etnomúsica \\
\hline & & $\begin{array}{l}47- \\
48\end{array}$ & Julio-diciembre & $\begin{array}{l}\text { La música en la Amazonía. 2. Música } \\
\text { popular en la selva del Perú }\end{array}$ \\
\hline 1990 & XIV & $\begin{array}{l}49- \\
52\end{array}$ & $\begin{array}{l}\text { Enero-diciem- } \\
\quad \text { bre }\end{array}$ & $\begin{array}{l}\text { Comunidades cristianas en la Amazonía: } \\
20 \text { ańos de historia. Homenaje al P. Anto- } \\
\text { nio Aladro García }\end{array}$ \\
\hline
\end{tabular}

El listado de los temas se elaboró con la información de la portada y contraportada de los números de la revista y se ha complementado con la información aparecida en CETA (1981, 1998 y 2004). 
Índice general de Shupihui: Revista Latinoamericana de Actualidad y Análisis (19761990)

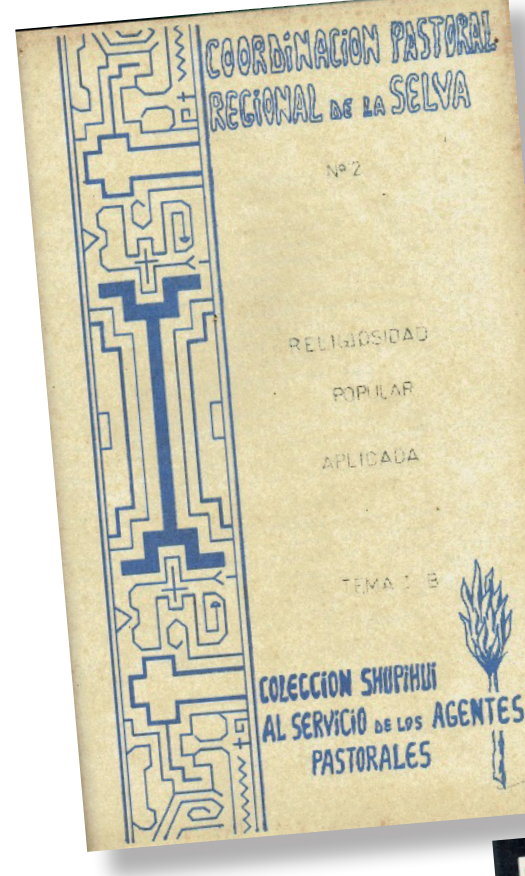

Figura 1. Shupihui N. ${ }^{\circ}$ 2, 1976. Archivo CAAAP-CENDOC

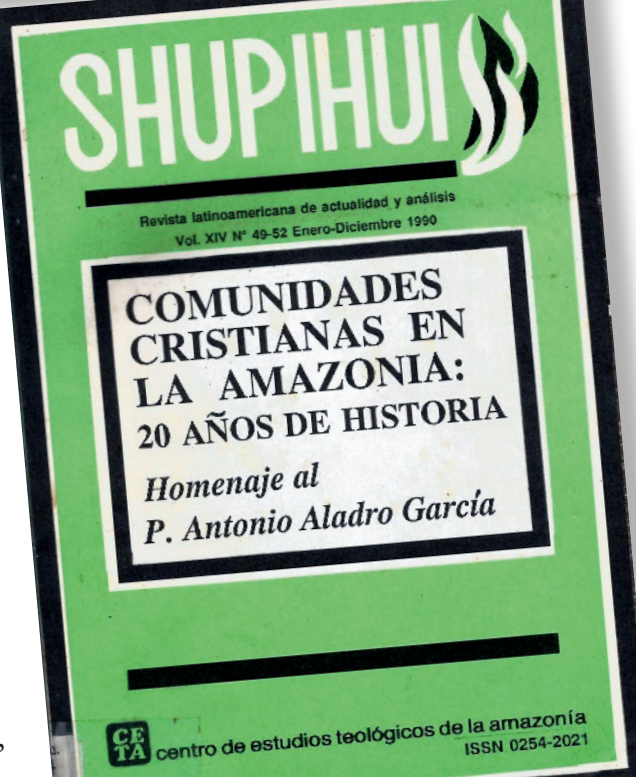

1990. Archivo IFEA-Biblioteca 


\section{ÍNDICE CRONOLÓGICO}

Volumen I. Número 1, abril-junio, 1976

La religiosidad popular, Tema: A

LA COORDINACIÓN. Introducción; s. p.

POBLETE, Renato. Aspectos sociológicos de la religiosidad popular; pp. 1-12.

GALILEA, Segundo. Evangelización de la religiosidad popular - Dialéctica de dos modelos pastorales; pp. 13-17.

GORSKI, Juan F. Miremos nuestra religiosidad; pp. 18-20.

BÜNTIG, Aldo J. Extracto: Interpretación motivacional del catolicismo popular; pp. 21-29.

VIDALES, Raúl y Kudo TOKIHIRO. Extracto: Práctica religiosa y proyecto histórico; pp. 30-40.

Volumen I. Número 2, julio-setiembre, 1976 La religiosidad popular aplicada, Tema: B

LA COORDINACIÓN. Introducción; s. p.

CASTILLO ARROYO, Javier. Manifestaciones de la religiosidad popular en el Perú; pp. 42-50.

HOORNAERT, Eduardo. Extracto: Guadalupe, evangelización y dominación; pp. 51-58.

HILLENBRAND, Hans. Extracto: Cuadernos T. S. Algunos aspectos de la religiosidad campesina; pp. 59-67.

DE UNCITI, Manuel. Umbamdismo: cristianismo a la afrobrasileña; pp. 68-75. 
Índice general de Shupihui: Revista Latinoamericana de Actualidad y Análisis (19761990)

Bibliografía sobre religiosidad popular en América Latina; pp. $1-4$.

Volumen I. Número 3, octubre-diciembre, 1976

Comunidades cristianas rurales

Introducción; s. p.

[Guía para los agentes de pastoral en la redacción de los informes], pp. 76-97.

\section{ANEXOS}

A. Reflexiones. II Encuentro de Pastoral Rural de la Selva, agosto de 1976; s. p.

B. Reflexiones. I Encuentro de Pastoral Rural de la Selva. Iquitos, agosto de 1976; s. p.

Volumen II. Número 4, enero-junio, 1977

Comunidades cristianas en América Latina: Experiencias y reflexiones

LA COORDINACIÓN GENERAL. Introducción; p. 1.

I Viaje por Centroamérica y algunos países andinos; pp. $408 \quad 3-23$.

II Una iglesia que nace del pueblo; pp. 24-32.

Volumen II. Número 5, julio-diciembre, 1977.

Pastoral indigenista en los países amazónicos

LA COORDINACIÓN. Presentación; p. 35. 
Una prehistoria de este encuentro; pp. 37-43.

Experiencias misioneras en el Brasil; pp. 45-57.

Experiencias misioneras entre los shuar del Vicariato de Méndez (Ecuador, Prov. Morona Santiago); pp. 59-64.

Breve informe sobre la realidad indígena venezolana; pp. 6569.

La situación misionera de la Amazonía boliviana; pp. 70-78.

Primer Encuentro Panamazónico de Pastoral Indígena. Documento Final; s. p.

\section{Volumen III. Número 6, enero-marzo, 1978}

Sectas cristianas en la selva del Perú

Presentación; pp. 1-3.

GARCIA RENDUELES, Manuel. Sectas cristianas en la selva del Perú; pp. 4-43.

Volumen III. Número 7, abril-junio, 1978

Partidos políticos en el proceso hacia la constituyente

RAMÍREZ RODRÍGUEZ, Rómulo. Introducción; pp. 4950.

LA COORDINACIÓN. Nota aclaratoria; p. 51.

DEL CASTILLO, Pedro. Acción Popular (A.P.); pp. 53-59.

Frente Nacional de Trabajadores y Campesinos (F.N.T.C.); pp. 61-68. 
Índice general de Shupihui: Revista Latinoamericana de Actualidad y Análisis (19761990)

Frente Obrero Campesino Estudiantil y Popular (F.O.C.E.P.); pp. 69-73.

PARDO M., Orison A. Partido Aprista Peruano (P.A.P.); pp. 75-80.

BARCIA G., Fernando. Partido Comunista Peruano (P.C.P.); pp. 81-87.

Partido Popular Cristiano (P.P.C.); pp. 89-96.

Partido Socialista Revolucionario (P.S.R.); pp. 97-102.

Unidad Democrática Popular (U.D.P.); pp. 103-107.

\section{Volumen III. Número 8, julio-diciembre, 1978 Grupos indígenas hoy}

El CAAAP. Presentación; pp. 7-8.

Declaración de Barbados II; pp. 9-11.

MORA, Carlos y Alberto CHIRIF. Comentario sobre la nueva ley de CC. Nativas (D.L. 22175); pp. 12-14.

GARCÍA-RENDUELES, Manuel. Ley de comunidades nativas y el desarrollo agropecuario de la selva y ceja de selva (D.L. 22175); pp. 15-29.

CIPA. Las comunidades nativas y la asamblea constituyente; pp. 30-33.

MARZAL, Manuel M. Indigenismo y constitución; pp. 34-53.

Documento suscrito por los cancilleres de países de cuenca amazónica; pp. 54-62. 
MERCIER, Juan Marcos y Gastón VILLENUEVE. Reflexiones en torno a la creación de "OFESIBE"; pp. 63-64.

Carta de los obispos y agentes de pastoral de la selva del Perú a la III Conferencia del Episcopado Latinoamericano, reunida en Puebla, México. (Texto final), pp. 65-67.

\section{Volumen IV. Número 9, enero-marzo, 1979 Puebla, culturas e indigenismo}

\section{PUEBLA, CULTURAS E INDIGENISMO}

SHUPIHUI. Presentación; pp. 9-12.

REGAN, Jaime. Puebla y la religión del pueblo; pp. 13-16.

GARCÍA, Joaquín. Fe, culturas e indigenismo en el documento de Puebla; pp. 17-30.

\section{DOCUMENTOS}

Discurso de Juan Pablo II en la inauguración de la II Conferencia Episcopal; pp. 33-48.

Discurso de Juan Pablo II a los indios en Oaxaca; pp. 49-52.

El indio brasilero que no pudo ir a Puebla; pp. 53-55.

El P. Jentel, mártir de la causa indígena; pp. 56-57.

Carta de los obispos a Don Oscar Romero, arzobispo de San Salvador; pp. 58-59.

CELAM-CNBB. Primer Encuentro Panamazónico de Pastoral Indigenista. Documento final; pp. 60-64. 
Índice general de Shupihui: Revista Latinoamericana de Actualidad y Análisis (19761990)

IV Asamblea Episcopal Regional de la Selva del Perú (Yurimaguas). Documento final; pp. 65-75.

\section{TEXTOS Y GLOSAS}

I.C.I. Se despiertan los indios; pp. 79-83.

MOLINA PALLOCCHIA, Oscar. Resolución Ministerial; pp. 84-85.

Testimonios sobre Puebla; pp. 86-92.

Selección de textos del Documento de Puebla; pp. 93-107.

4. AL RITMO DE LA NOTICIA; pp. 109-127.

\section{BIBLIOGRAFÍA}

Alegre, Pascual. Tashorintsi. Tradición oral machiguenga. Lima. Centro Amazónico de Antropología y Aplicación Práctica, 1979, 77 pp.; p. 131 (J. V.).

Amazonía Peruana, V. II, N.o 3 (octubre, 1978), 238 pp., Lima, Centro Amazónico de Antropología y Aplicación Práctica; p. 131.

Mercier, Juan Marcos, Nosotros los napu-runas. Mitos e historia. 1979, 379 pp. Publicaciones CETA-Iquitos; p. 132.

Volumen IV. Número 10, abril-junio, 1979

Vida consagrada en América Latina

\section{VIDA CONSAGRADA EN AMERICA LATINA}

SHUPIHUI. Presentación; pp. 139-140. 
ANTONCICH, Ricardo. Una vida religiosa por los caminos de Puebla; pp. 141-157.

DE LORA, Cecilio. 20 años de la "CLAR”; pp. 158-160.

GALILEA, Segundo. Espiritualidad, pastoral y vida religiosa; pp. 161-170.

\section{DOCUMENTOS}

VII Asamblea General de la “CLAR”; pp. 173-187.

SAGRADAS CONGREGACIONES. "Mutuae Relationes"; pp. 188-193.

Organización Kichwaruna Wingurina; pp. 194-196.

\section{TEXTOS Y GLOSAS}

Algunas experiencias de vida religiosa en la vida de la Iglesia amazónica; pp. 199-205.

Selva peruana; pp. 206-207.

Programa de unidades de producción para comunidades nativas; pp. 208-209.

4. AL RITMO DE LA NOTICIA

Movimientos populares y sindicales; pp. 213-221.

\section{BIBLIOGRAFÍA}

Ortiz, Dionisio. Monografía del Vicariato de San Ramón (Chanchamayo), 192 pp., Lima 1979; p. 225.

Porantim, Em Defesa da Causa Indígena. Órgano informativo de defensa de la causa indígena del Conselho Indigenis- 
Índice general de Shupihui: Revista Latinoamericana de Actualidad y Análisis (19761990)

ta Missionario (CIMI) da Amazonia. Año II, N.o 8, Junio 1979. Manaus, p. 225.

Nimuendaju-Unkel, Curt. Los mitos de creación y destrucción del mundo como fundamentos de la religión de los apapokuva-guaraní. Juergen Riester G. Centro Amazónico de Antropología y Aplicación Práctica (CAAAP). Col. Serie Antropológica I, Lima 1978; p. 226.

Orrego Villacorta, Eduardo y otros. Amazonía, conquista del presente. Lima 1979; pp. 226-227.

Volumen IV. Número 11, julio-setiembre, 1979 Los nuevos caminos de la medicina

\section{TEMAS}

SHUPIHUI. Presentación; pp. 237-239.

BENNETT, S.W. y R. U. CARCAVALLO. Sistemas ecológicos y salud humana; pp. 240-249.

ORTEGA, Fernando. Medicina científica y medicina tradicional; pp. 250-255.

DOBKIN DE RÍOS, Marlene. Relación entre las creencias en la brujería y la enfermedad psicosomática; pp. 256-264.

GARCÍA, Joaquín. Apuntes para una reflexión sobre la pastoral sanitaria; pp. 265-271.

Estadística de personal o establecimientos de salud en la selva a cargo de la iglesia; pp. 272-273.

\section{DOCUMENTOS}


Carta de los kichwaruna sobre el I.L.V.; pp. 277-278.

Primer Encuentro Intervicarial de Pastoral Sanitaria. Documento final; pp. 279-286.

Consejo Indigenista Misionero. Documento final de la III Asamblea del CIMI; pp. 287-292.

\section{TEXTOS Y GLOSAS}

GUALLART, José María. La carta que llegó tarde a Puebla; pp. 295-298.

Testimonios de los misioneros de Maynas sobre etnomedicina; pp. 299-302.

VICARIATO APOSTÓLICO DE PUCALLPA. Una experiencia de pastoral sanitaria; pp. 303-309.

PERMADINGER, Amneliene. La armonía del alma, el cuerpo y la naturaleza; pp. 310-312.

El caso Herzog-Wawaim; pp. 313-324.

4. AL RITMO DE LA NOTICIA

Movimientos populares; pp. 327-338.

\section{BIBLIOGRAFÍA}

Rarrazaval, Diego. Religión del pobre y liberación en Chimbote. Editorial: Centro de Estudios y Publicaciones (CEP). Lima, 1978; p. 341.

Amazonía Peruana. Vol. 2, N. ${ }^{\circ}$ 4, enero de 1979; p. 342.

Gutiérrez, G. La fuerza histórica de los pobres. Edit.: Centro de Estudios y Publicaciones (CEP) Lima, 1979; p. 342. 
Índice general de Shupihui: Revista Latinoamericana de Actualidad y Análisis (19761990)

Volumen IV. Número 12, octubre-diciembre, 1979 Movimientos populares en el Perú y en América Latina

\section{TEMAS}

SHUPIHUI. Presentación; pp. 351-353.

KLAIBER, Jeffrey L. Movimientos de campesinos en América Latina, siglo XVI-XX; pp. 354-359.

BALLÓN, Eduardo. El movimiento popular: de la derrota de enero a la victoria de julio; pp. 360-373.

GARCÍA, Joaquín. Ensayo de cronología de los movimientos populares en la Amazonía Peruana; pp. 374-384.

SICCHAR, Víctor Rubén. Las luchas populares en Iquitos (cronología provisoria de 1959-1979); pp. 385-387.

CABIXI, Daniel M. Las asambleas indígenas como arma de lucha; pp. 388-392.

\section{DOCUMENTOS}

III Encuentro de Pastoral Rural de la Selva, pp. 395-404.

Encuentro de Animadores de Comunidades Cristianas del Campo; pp. 405-410.

416

Compromiso cristiano para una Nicaragua libre. Carta pastoral del episcopado Nicaragüense; pp. 411-421.

\section{TEXTOS Y GLOSAS}

Carta abierta al Sr. Werner Herzog; pp. 425-426.

Mas sobre el caso Herzog-Wawaim; pp. 427-429. 
CEREZO BARREDO, Maximino. Nuestra opción por la comunidad desde Puebla; pp. 430-443.

CEREZO BARREDO, Maximino. La iglesia que acompaña al pueblo. Experiencias de lucha en San Martín; pp. 444448.

\section{AL RITMO DE LA NOTICIA}

Transferencia: amenazas y acusaciones; pp. 451-459.

\section{BIBLIOGRAFÍA}

Quehacer. Realidad nacional - Problemas y alternativas. Revista publicada y editada por el Centro de Estudios y Promoción del Desarrollo (DESCO). Lima. Sin fecha; p. 463 (B. D.).

Chumap Lucia, Aurelio y Manuel García Rendueles. "Duik múun..." Universo mítico de los Aguaruna, 2 tomos. Edita Centro Amazónico de Antropología y Aplicación Práctica, Serie Antropológica II, Lima, 1979; pp. 463-464 (B. D.).

Villarejo, Avencio. Así es la selva. Tercera edición. Edita: Publicaciones CETA. Iquitos, 1979; pp. 464-465.

\section{Volumen V. Número 13, enero-marzo, 1980 La danza de las ofertas políticas a la Cenicienta}

SHUPIHUI. Presentación; pp. 475-478.

\section{TEMAS}

Agrupaciones políticas del país; pp. 479-481.

Partidos políticos y sus programas para la Amazonía; pp. 482-536. 
Índice general de Shupihui: Revista Latinoamericana de Actualidad y Análisis (19761990)

PEASE GARCÍA, Henry. Triunfo popular: la alternativa se aleja; pp. 537-550.

\section{DOCUMENTOS}

Declaración del episcopado sobre el proceso electoral; pp. 553-557.

Carta de "Survival International" al Presidente de la República; pp. 558.

Declaración de la Unidad Democrática Popular; pp. 559563.

Documentos del episcopado latinoamericano sobre fe y política; pp. 564.

\section{TEXTOS Y GLOSAS}

Problemática del campesino de San Martín; pp. 567-569.

Hechos sucedidos en la comunidad campa de San Ramón de Pangoa; pp. 570-577.

Telegrama a la conferencia episcopal de El Salvador; pp. 578.

Fiesta Kichwaruna de "Diamante Azul”; pp. 579-581.

Denuncia al Instituto Lingüístico de Verano; pp. 582-583.

418

4. AL RITMO DE LA NOTICIA

5. BIBLIOGRAFÍA

Sole Roma, José María. Ministros de la Palabra, 3 tomos. Edita: Editorial Herder. Barcelona, 1979; p. 605 (J. M. A.). 
Santa María, Pedro. De Pucallpa a Tingo María, explorando las Pampas de Sacramento. Edita: Centro Amazónico de Antropología y Aplicación Práctica (CAAAP). Serie Ensayos, N. ${ }^{\circ}$. Lima, 1979; p. 605 (J. M. A.).

El Salvador. Un pueblo perseguido. Testimonios de cristianos. Centro de Estudios y Publicaciones CEP. Lima 1980; p. 606 (J. M. A.).

Salinas, Maximiliano y Diego Irarrazabal. Hacia una teología de los pobres, CEP 1980; p. 606 (J. M. A.).

Volumen V. Número 14, abril-junio, 1980

Problemas y esperanzas de la familia

\section{TEMAS}

SHUPIHUI. Presentación; pp. 149-152.

ZUMARÁN, Rosa María. Aproximaciones al estudio de la economía de la familia campesina en el bajo Amazonas; pp. 153-164.

REGAN, Jaime. La familia y la religión del pueblo; pp. 165170.

SAN ROMÁN, Jesús Víctor. Perspectiva histórica de la familia en la Amazonía; pp. 171-174.

PITRU, R. y C. SHÁKAI, F. TUISTS. Un modelo de familia nativa: La familia shuar; pp. 175-181.

GARCÍA, Joaquín. Perspectiva utópica de la familia; pp. 183-198.

El servinakuy; pp. 199-202. 
Índice general de Shupihui: Revista Latinoamericana de Actualidad y Análisis (19761990)

Muestra estadística sobre la situación legal de la familia en el Napo y bajo Amazonas; pp. 203-210.

\section{DOCUMENTOS}

Documentos sobre la problemática de los campas; pp. 213-219.

Documento sobre las comunidades ashaninkas del río Tambo; pp. 220-221.

La pastoral de la familia en la Amazonía. Documento de la V Asamblea Episcopal Regional de la Selva; pp. 220-241.

Declaración de los obispos de la selva del Perú sobre los problemas de la tierra; pp. 242-244.

Primer Encuentro Indigenista del Cono Sur. Documento final; pp. 245-247.

Programa radial Cristo Compañero, una experiencia de comunicación en Pucallpa; pp. 248-251.

PRELATURA DE MOYOBAMBA. Nuevo modelo de familia que aparece como resultante; p. 252.

\section{TEXTOS Y GLOSAS}

A propósito de un estudio sobre la selva alta; pp. 255-257.

420 REGAN, Jaime. En torno a una obra sobre el catolicismo popular en Brasil; pp. 258-260.

GARCÍA, Joaquín. Oración al borde del 18, poema; pp. 261-263.

Resumen oficial del cómputo departamental de Loreto en las elecciones; pp. 264-266. 
MERCIER, Juan Marcos. Consejos de los kichwas a los jóvenes esposos; pp. 267-269.

Acción Popular aclara al Shupihui; pp. 270-271.

4. AL RITMO DE LA NOTICIA; pp. 273-286.

5. BIBLIOGRAFÍA

Ortiz, Dionisio. Monografía del Purús. Lima, 1980; p. 289.

Andenes. Boletín de las Comunidades Cristianas del Campo. Número 6, Lima, abril de 1980; p. 289 (J. RAMÍREZ).

Equipo de Reflexión Teológico Pastoral del CELAM: La familia a la luz de Puebla. Aporte del CELAM para el Sínodo Episcopal de 1980. CELAM. Bogotá, 1980; p. 289 (J. RAMÍREZ).

Volumen V. Número 15, julio-setiembre, Especial, 1980 Hacia la conquista de la Amazonía (I)

\section{DOCUMENTOS}

SHUPIHUI. Presentación; pp. 297-298.

Documentos de base; pp. 299-328.

Documentos de iglesia; pp. 329-354.

Otros documentos; pp. 355-374.

2. APORTES VARIOS

La selva sigue de remate; pp. 377-378.

Empresas capitalistas: "La selva es nuestra”; pp. 379-387. 
Índice general de Shupihui: Revista Latinoamericana de Actualidad y Análisis (19761990)

Se avizora un boom del caucho; pp. 388-390.

Asamblea de delegados, Federación Campesina de Coronel Portillo; pp. 391-392.

Informativo pro defensa de tierras nativas; pp. 393-394.

Documentos y otros aportes sobre la invasión a la Amazonía publicados por "Shupihui" (1977-1980); pp. 395-396.

J. G. Vientos del pueblo; pp. 397-398.

3. AL RITMO DE LA NOTICIA; pp. 399-412.

4. BIBLIOGRAFÍA

Cebero, Palomino. El Instituto Lingüístico de Verano: Un fraude. Ediciones Rupa, Lima, 1980. 81 pp.; p. 415 (Annette R. DE URIARTE).

Nicaragua a un año de la victoria. Documento-TestimoniosReflexiones. Centro de Estudios y Publicaciones (CEP). Lima, 1980; p. 415 (Bibiana DAIGLE).

Klaiber, Jeffrey L. Religión y revolución en el Perú, 18241976. Universidad del Pacífico. Departamento de Humanidades. Lima, 1980. Traducción del original en inglés publicado en Indiana, 1977; p. 416 (Bibiana DAIGLE).

422 Amazonía Indígena. Boletín de Análisis. COPAL - Solidaridad con los grupos nativos. Número 1. Julio 1980. Lima; p. 417 (Joaquín GARCÍA).

Volumen V. Número 16, octubre-diciembre, Especial, 1980

Hacia la conquista de la Amazonía (II) 
SHUPIHUI. Presentación; pp. 423-424.

ALADRO, Antonio. Pequeña crónica de un importante coloquio; pp. 425-426.

\section{TEMAS}

DÁVILA HERRERA, Carlos A. La colonización en el proceso de desarrollo histórico de la selva peruana; pp. 429-435.

Relación de algunos contratos de evaluación y exploración forestal y otras concesiones de tierras; pp. 436-441.

BASURTO C., Rosario. Algunas consideraciones sobre la actual política de penetración capitalista en la selva: la región Pichis-Palcazu, el gobierno y la AID; pp. 442-450.

MOORE, Thomas. Transnacionales en Madre de Dios: implicancias para las comunidades nativas; pp. 451-463.

SAN ROMÁN, Jesús Víctor. Mercantilismo y penetración capitalista en la selva; pp. 464-471.

PONTONI B., Alberto. Recursos petroleros, excedentes y desarrollo regional en la Selva norte; pp. 472-484.

VILLANUEVA ARÉVALO, César. Penetración capitalista y las rutas de la droga; pp. 485-495.

ZARZAR, Alonso. Fronteras de penetración y consecuencias en las etnias del bajo Urubamba; pp. 496-510.

SCAZZOCCHIO, Françoise. Del bosque nativo a propiedad: El desarrollo de la Amazonía, ¿Para quién?; pp. 511522 . 
Índice general de Shupihui: Revista Latinoamericana de Actualidad y Análisis (19761990)

CAMINO, Alejandro. Ecología e ideología en la cultura nativa del bosque tropical; pp. 523-530.

PENNANO ALLISON, Guido. Aproximación teórica al caso del caucho; pp. 531-542.

DELRAN COUSY, Guido. Interrogantes sobre el porvenir del agro-andino; pp. 543-550.

TAVARES MONTEIRO, Silvio. El proceso de penetración capitalista en la Amazonía brasilera; pp. 551-564.

\section{DOCUMENTOS}

Declaración de Iquitos, Coloquio sobre la Nueva Conquista de la Selva; pp. 567-569.

Encuentro Ecuménico Panamazónico de Pastoral Indigenista: Documento final; pp. 570-577.

\section{BIBLIOGRAFÍA}

Melia, Bartomeu. Educação Indígena e Alfabetização. Edições Loyola. São Paulo, 1979. Coleção "Missão Aberta"; p. 581 .

Suess, Paulo. Em defesa dos povos indígenas. Documentos e Legislação Edições Loyola. São Paulo, 1980. Coleção "Missão Aberta”; p. 581.

Lenz, Matías M. y otros. A Igleja e a Propiedade da Terra no Brasil (Comentarios ao documento da CNBB: Igleja e Problemas da Terra, Itaicí, 1980). Ediçóes Loyola. São Paulo, 1980; p. 582 (Bibiana DAIGLE).

Encuentro de Riobamba (Mayo 1979). Estudio sobre Puebla. Edit. CEP. Lima, 1980; p. 582 (Bibiana DAIGLE). 
Volumen VI. Número 17, enero-marzo, 1981 Iglesia e indigenismo en América Latina

Presentación; p. 5.

1. TEMAS

GARCÍA, Joaquín. Dom Pedro Casaldáliga habla de la iglesia; pp. 9-23.

CHIRIF TIRADO, Alberto. La última frontera campa; pp. $25-43$.

RUMRRILL, Róger. El Pacto Amazónico o la "doctrina Monroe" brasileña; pp. 45-55.

VILLANUEVA ARÉVALO, César. Ley de Promoción y Desarrollo Agrario, una ley para empresarios y no para campesinos; pp. 57-61.

\section{DOCUMENTOS}

Memorial dirigido a la Hna. Sagrario, Supervisora de Promotores de Salud; p. 65-69.

Mensaje del Episcopado Peruano; pp. 70-77.

COMITÉ COORDINADOR DE LAS COMUNIDADES NATIVAS DEL UCAYALI. Asamblea General de Delegados del Río Ucayali y sus Afluentes; pp. 78-89.

Comisión Pro-Defensa de las Tierras Nativas, a la opinión pública; pp. 90-91.

"Temas y figuras", comunicado a la opinión pública; pp. 9293. 
Índice general de Shupihui: Revista Latinoamericana de Actualidad y Análisis (19761990)

Documento de la XIX Asamblea General de la CNBB; pp. 94-98.

Convocatoria a la II Asamblea Provincial de Delegados de la Federación Campesina de Maynas; pp. 99-100.

Tres documentos relativos a las reivindicaciones de Loreto; pp. 101-112.

\section{TEXTOS Y GLOSAS}

El espinoso tema de "Temas y figuras"; pp. 115-116.

Escuelas campesinas de la CCP; pp. 116-117.

La Amazonía sigue de moda; pp. 118-120.

4. AL RITMO DE LA NOTICIA; pp. 123-137.

\section{BIBLIOGRAFÍA}

Estatutos del Congreso de Comunidades Nativas Amuesha. Valle Palcazu-Villa Rica-Oxapampa. Abril de 1980; p. 141 (Joaquín GARCÍA).

Iriarte de Aspurz, Lázaro. Aguarico. Un empeño de roturación evangélica en dos tiempos 1954-1959. CICAME, Prefectura Apostólica de Aguarico. Quito, 1980; p. 141 (Joaquín GARCÍA).

Kapsoli, Wilfredo. El pensamiento de la Asociación Pro-Indígena. Serie: Debates Rurales. Centro de Estudios Rurales Andinos Bartolomé de las Casas, Cuzco, 1980. 153 pp.; p. 142 (Rosa María ZUMARÁN).

ORDELORETO: Memoria del desarrollo. Proceso Editores. Lima 1980; p. 142 (Joaquín GARCÍA). 
Ortiz de Villalba, Juan Santos. Los últimos huaorani. Publicaciones CICAME. Quito, 1980. 166 pp.; p. 143 (Francisco GARCÍA).

Pontoni, Alberto. Políticas y legislación petrolera en el Perú. Cuaderno de IPEP. Serie: Transnacionales y petróleo-1. Instituto Peruano de Estudios del Petróleo. Lima 1981. Mimeo; pp. 143-144 (Joaquín GARCÍA).

Barbira-Scazzochio, Francoise. Land, People and Planning in Contemporary Amazon. Center of Latin American Studies, Occasional Publication N. ${ }^{\circ}$ 3, Universidad of Cambridge. 1980; p. 144 (Bibiana DAIGLE).

\section{Volumen VI. Número 18, abril-junio, 1981 La Amazonía en el cine}

Presentación; p. 149.

1. TEMAS

BLANCO, Desiderio. Presencia de la Amazonía en las imágenes del cine peruano; pp. 153-171.

GARCÍA, Joaquín. Rasgos históricos del cine en Iquitos y en la región; pp. 173-182.

LLANOS, Rogelio. Apuntes para un trabajo sobre el cine y la Amazonía; pp. 183-187.

ADRIANZÉN, Francisco. La selva vista a través del cortometraje peruano; pp. 189-194.

ROBLES GODOY, Armando. Selva y cine peruanos; pp. 195-198. 
Índice general de Shupihui: Revista Latinoamericana de Actualidad y Análisis (19761990)

GARCÍA, Joaquín. Herzog. Visiones y descargos de un cineasta; pp. 199-202.

Dos preguntas a Nora de Izcue; pp. 203-206.

LLANOS, Rogelio. La selva como pretexto para un ejercicio cinematográfico; pp. 207-212.

CAMINO, Alejandro. Integrati-non integrati: una aproximación al cine antropológico en la Amazonía peruana; pp. 213-221.

Filmografía de la Amazonía peruana; pp. 223-236.

\section{DOCUMENTOS}

Demandas de los cocamillas; pp. 239-244.

Pronunciamiento de la Federación Campesina de Maynas (FECADEMA); pp. 245-249.

Denuncia de la comunidad nativa "Sepahua"; pp. 250-251.

Cronología de las acciones del Frente de Defensa del Pueblo de Loreto (Junio de 1980-Enero de 1981); pp. 252-261.

\section{TEXTOS Y GLOSAS}

DÁVILA HERRERA, Carlos. La cinematografía social y el 428 cine antropológico; pp. 265-272.

DE IZCUE, Nora. El viento del ayahuasca (film en proceso de realización); pp. 273-278.

HERZOG, Werner. Fitzcarraldo (Actualmente en filmación en la selva del Perú); pp. 279-286.

Cinemas de Iquitos (1898-1981); pp. 287-288. 
4. AL RITMO DE LA NOTICIA; pp. 289-298.

\section{BIBLIOGRAFÍA}

Amazonía Peruana. Revista del Centro Amazónico de Antropología y Aplicación Práctica (CAAAP) Vol. III, N. ${ }^{\circ}$, 1980; p. 301.

Carelli, Vincent y Milton Severiano. Mão branca contra o povo Cinza. Vamos matar este indio? Edit. Brasil Debates 1980. A presentação Dom Tomás Balduino; p. 301.

En defensa de los pueblos indígenas. Colección de documentos acerca de la problemática indígena en Latinoamérica. Edit. CELADEC. Lima, 1980; p. 301.

O Trabalhador Rural. Boletim periódico CONTAG (Confederação Nacional dos trabalhadores na Agricultura) Año 13 (1981) Número especial; p. 301.

Chaumeil, J. P. Historia y migraciones de los yaguas de finales del siglo XVII hasta nuestros días. Edit. CAAAP: Serie Antropológica, N. ${ }^{\circ} 3$. Lima, 1981; p. 302.

Ballón Aguirre, Francisco. Etnia y represión penal. Edit. CIPA. Lima, 1980; p. 302.

Grupo de Investigaciones Económicas. Repercusión Económica del Puerto Libre. Mimeo. 16 págs. Iquitos, 1980; p. 302.

Panorama. Revista del Seminario de Estudios Antropológicos de la Selva (S.E.A.S.) de la Universidad Nacional Mayor de San Marcos. Año 3, N. ${ }^{\circ}$ (diciembre de 1980); p. 303

Chinicuro, Sumac Quinba. Dibujos de Félix Erentxun y Ángel González. Edit.: CICAME, Centro Cultural de la Prefec- 
Índice general de Shupihui: Revista Latinoamericana de Actualidad y Análisis (19761990)

tura Apostólica de Aguarico. Pompeya-Río Napo (Ecuador) 1980. Mimeo.; p. 303.

Amanecer. Reflexión cristiana en la nueva Nicaragua. Boletín del Centro Ecuménico Antonio Valdivieso N. ${ }^{\circ}$ 1, mayo de 1981. Director: Teófilo Cabestrero; diagramador y dibujante: Maximino Cerezo. Managua (Nicaragua); pp. 303-304.

Comisión Evangélica Latino Americana de Educación Cristiana (CELADEC). Últimos títulos publicados; p. 304.

\section{Volumen VI. Número 19, julio-setiembre, 1981 La literatura de la Amazonía peruana}

Presentación; p. 309.

\section{TEMAS}

RAMÍREZ, Luis Hernán. Aproximación a la obra de Francisco Izquierdo Ríos; pp. 313-318.

PORTAL, Magda. El escritor de los niños; pp. 319-321.

RUMRRILL GARCÍA, Róger. El memorioso Pancho Izquierdo; pp. 323-331.

RUMRRILL GARCÍA, Róger. Una “Trocha” para la literatura amazónica; pp. 333-338.

GARCÍA SÁNCHEZ, Joaquín. Perfil bibliográfico de la literatura en la Amazonía Peruana; pp. 339-374.

\section{DOCUMENTOS}

La FUNAI y la hacienda Tapiraguaia invaden a los tapirape; pp. 377-380. 
De atropellos burocráticos a los derechos de los campa; pp. 381-399.

Los derechos de los pueblos indígenas y de la iglesia; pp. 401403.

\section{TEXTOS Y GLOSAS}

Breve antología de poesía y narraciones en la Amazonía; pp. 407-482.

F.B.T.: Conspiración mundial; pp. 483-484.

Mesa Redonda sobre Fronteras Vivas; pp. 485.

Primera Semana de Cine Amazónico; p. 486.

Fórum Regional sobre el Desarrollo de la Amazonía; p. 487.

4. AL RITMO DE LA NOTICIA; pp. 489-502.

\section{BIBLIOGRAFÍA}

Runapura, Hoja de información de las comunidades kichwas del río Tigre, 1 (marzo de 1981), 2 (setiembre 1981). Textualmente dice el subtítulo: "Sale cuando puede"; p. 505.

Indians, Missionaries and the Promised Land. Edit. Survival International, Londres, Inglaterra. Octubre 1980; p. 505.

Aijiv Juanka, Uchi Jesúsjai. Akankamu 1, uwi 1, uwi 2. Shuara Tuntuirini Shuarnum Unuimiatai. Sukunum, 1981; p. 505

Boletín del Grupo Internacional de Trabajo sobre Asuntos Indígenas (IWGIA). Vol. 1 (1981); p. 506. 
Índice general de Shupihui: Revista Latinoamericana de Actualidad y Análisis (19761990)

ORDELORETO: Unidad de Encuestas y Demografía. Población y superficie; p. 506.

Runciman T., María L. y Rosa Aguilera R. Artesanía femenina en Santa Clara de Nanay y Santo Tomas. ORDELORETO. Dirección Regional de Agricultura. División de Estudios y Proyectos de la Dirección de Reforma Agraria y A.R. Iquitos, 1981. Mimeo.; p. 506.

Baca Polanco, Amparo. Estudio socio-económico de la Isla de Iquitos y Padre Isla. ORDELORETO. Dirección Regional de Agricultura, División de Estudios y Proyectos de la Dirección de Reforma Agraria y Asentamiento Rural. Iquitos, Abril, 1981 Mimeo.; p. 507.

Bianchi, César. El shuar y el ambiente. Conocimiento del medio y cacería no destructiva. Ilustraciones de Tonino Clemente. Colección Mundo Shuar. 1981; p. 507.

Pontoni, Alberto. Transnacionales y petróleo en el Perú. Análisis de las políticas petroleras: 1968-1980. Edit. Centro de Estudios para el Desarrollo y la Participación (CEDEP). Serie Realidad Nacional. Lima, 1981; p. 508.

Informes CAV. Servicio del Centro Ecuménico Antonio Valdivieso. Managua. Nicaragua. I (Mayo de 1981); p. 508.

\section{Volumen VI. Número 20, octubre-diciembre, 1981} II Coloquio sobre la Nueva Conquista de la Selva

Presentación; p. 513.

\section{TEMAS}

GASCHÉ, Jurg. La región del bajo Amazonas y zonas fronterizas; pp. 517-527. 
Problemas de la familia kichwa - Informe del alto Napo; pp. 529-531.

VILLANUEVA, César. Realizando una alternativa con el pueblo. La experiencia de San Martín; pp. 533-550.

LIRIO, José. Organización Central Aguaruna del Alto Marañón, OCAAM; pp. 551-566.

CENTURIÓN, Segundo. Federación Agraria "Selva Maestra” del departamento de San Martín; pp. 567-571.

TRAPNELL, Lucy. La región del Ene-Tambo en el punto de mira; pp. 573-601.

MORA, Carlos. El proceso actual de penetración en el Pichis-Palcazu; pp. 603-618.

ARAGÓN, Efraín. Infraestructura vial y capitalismo en la conquista de la selva peruana; pp. 619-627.

GARCÍA, Genaro. Zona franca y desarrollo regional; pp. 629-634.

\section{DOCUMENTOS}

Solidaridad con la iglesia de Juli (Puno); pp. 637-638.

Manifiesto de los indígenas amazónicos del Perú ante la Primera Reunión Amazónica de Asuntos Indígenas; pp. 639642.

¡SOS! Un pueblo se está quedando ciego. Onchocercosis en Esmeraldas; pp. 643-645.

Fragmentos de las conclusiones y recomendaciones de la Primera Reunión Técnica sobre Problemas de las Poblaciones 
Índice general de Shupihui: Revista Latinoamericana de Actualidad y Análisis (19761990)

Indígenas de la Región Amazónica; pp. 646-657.

II Coloquio sobre la Nueva Conquista de la Selva; pp. 658668.

\section{TEXTOS Y GLOSAS}

Informe de la Comisión Pro Defensa de las Tierras Nativas y Campesinas de la Amazonía; pp. 671-672.

+ P. Isidro Salvador Gutiérrez en la paz de Cristo (19141981); p. 673.

Carta notarial aclaratoria. Párroco de Cutivireni; pp. 674-680.

4. AL RITMO DE LA NOTICIA; pp. 681-690.

\section{BIBLIOGRAFÍA}

Cultura Popular. Revista Latinoamericana de Educación Popular. CELADEC. Lima. 1981; p. 693.

Hvalkof, Soren y Peter Aaby. Is God an American? ¿Dios es un americano? Perspectiva antropológica de la labor misionera del Instituto Lingüístico de Verano. IWGIA y Survival International. Copenhagen, Dinamarca. 1981; p. 693.

Tierra de dolor y esperanza. Testimonios: Bolivia 1976434 Perú, 1981; pp. 694-695.

Ministerio de Salud. El aborto en los establecimientos de salud del Perú. Dirección General de Salud Materno Infantil y Población. Lima, 1980; p. 694.

Rojas, Ibico. Expansión del quechua. Primeros contactos con el castellano. Ediciones Signo. Lima, 1980; p. 695. 
Guallart, José María. Fronteras vivas. Poblaciones indígenas en la cordillera del Cóndor. Centro Amazónico de Antropología y Aplicación Práctica (CAAAP) Lima, 1981; p. 696.

Volumen VII. Número 21, enero-marzo, 1982

Petróleo y transnacional; culturas indígenas y evangelización

Presentación; p. 3.

\section{TEMAS}

PONTONI, Alberto. Perspectivas de la penetración petrolera; pp. 7-12.

ZUMARÁN, Rosa María. El estado de las transnacionales; pp. 13-29.

REMY, María Isabel. Desplazamientos de población de la sierra a la selva; pp. 31-39.

Avance colonizador en Ecuador; pp. 41-46.

SUESS, Paulo. Culturas indígenas y evangelización; pp. 4764.

\section{DOCUMENTOS}

Mensaje de los obispos del Perú al pueblo de Dios; pp. 6772.

Carta pastoral de los obispos de la selva del Perú; pp. 73-95.

\section{TEXTOS Y GLOSAS}

FAUST, Astrid. La visión europea del problema indígena; pp. 99-105. 
Índice general de Shupihui: Revista Latinoamericana de Actualidad y Análisis (19761990)

DE IZCUE, Nora y Daniel PACHECO. El cine y su responsabilidad con la Amazonía; pp. 106-109.

I Encuentro Nacional de Pueblos Indígenas; pp. 109-110.

Campesinos, maíz, sangre inocente (Los hechos); pp. 111114.

Campesinos, maíz, sangre inocente (Reflexión cristiana); pp. 115-116.

Últimos pronunciamientos en torno a los sucesos de Tarapoto; pp. 117-118.

Asociación de docentes de la U.N.A.P. (Comunicado); pp. 118-120.

Declaración ante los sucesos de Polonia; pp. 121-122.

La civilización del cabello corto; pp. 122-124.

4. AL RITMO DE LA NOTICIA; pp. 125-136.

\section{BIBLIOGRAFÍA}

Ortiz, Dionisio. La montaña de Ayacucho, Lima 1981; p. 139.

Baca P., Amparo. El turismo y las poblaciones nativas. OR436 DELORETO; División de Estudios y Proyectos. Iquitos. 1981; pp. 139-140.

Diagnostico socio-económico de la sub-zona San Lorenzo V. Documento de trabajo ORDELORETO. Oficina Regional de Planificación. Iquitos, 1981; p. 140. 
Medina, M. Elena y Róger Rumrrill. Acerca del Pacto Amazónico. Centro de Investigación y Promoción Amazónica (CIPA) Lima 1981; p. 141.

Rondon Amarante, Elizabeth Aracy y Verónica Nizzoli. Precisamos un chao. Depoimentos Indígenas. Ediciones Loyola. São Paulo 1981; p. 142.

Tavares Monteiro, Silvio. Anotacóes para una historia rural do meio Amazonas. Emater AM. Manaus, 1981; p. 142.

Volumen VII. Número 22 abril-junio, 1982 El canon, garantía para la defensa de nuestras fronteras

Presentación; p. 145.

\section{TEMAS}

D'ONADIO, Antonio. El canon es garantía para la defensa de nuestras fronteras y el desarrollo de nuestro departamento; pp. 149-158.

SOTO, Julio. Ecología de la salud en comunidades nativas de la Amazonía peruana; pp. 159-172.

\section{DOCUMENTOS}

Informe sobre la situación de las tierras de la comunidad nativa de Tsachopen, presentado a la CIPA. Comisión Pro-Defensa de Tierras Nativas y Campesinas de la Selva-Noviembre 2, 1981; pp. 175-190.

Decreto por el que el gobierno ecuatoriano cancela el convenio con el Instituto Lingüístico de Verano; pp. 191-194. 
Índice general de Shupihui: Revista Latinoamericana de Actualidad y Análisis (19761990)

Síntesis de los temas tratados en el Primer Congreso Indígena Nacional de Colombia; pp. 195-202.

Misioneros extranjeros en el Perú se pronuncian sobre la guerra por las islas Malvinas; pp. 203-205.

\section{TEXTOS Y GLOSAS}

III Congreso Nacional Misionero de Ecuador; pp. 209-211. 4. AL RITMO DE LA NOTICIA; pp. 213-221.

\section{BIBLIOGRAFÍA}

Servicio documental El Salvador al filo de la esperanza. Fundación Fernando Velasco-CELADEC. Enero 1982; p. 225.

Directorio de comunidades nativas. Edita: Dirección de Reforma Agraria y Asentamientos Rurales, Ministerio de Agricultura. Iquitos 1980; p. 225.

Manual du promoteur de la santé. Assistance Médicale Internationale. Impreso en Canadá; p. 225.

Panaifo Texeira, Arnaldo. Cuentos... y... algo más. Lima 1981 ; p. 226.

Sobrino, Jon. Oscar Romero, Profeta y mártir de la liberación. Centro de Estudios y Publicaciones (CEP) Lima 1981; 438 p. 226.

Cabezas, Antonio y Amable Rosario. La emisora regional para el desarrollo. Editora Andina Quito 1980; p. 227.

Diagnostico socio-económico de la sub-zona de Nauta IV. Documento de trabajo ORDELORETO. Oficina Regional de Planificación. Iquitos 1981; pp. 227-228. 


\section{Volumen VII. Número 23-24, julio-diciembre, Extraordi- nario, 1982 \\ Homenaje al Padre Jesús Víctor San Román}

SHUPIHUI. Presentación; pp. 235-236.

Datos biográficos del P. Jesús Víctor San Román (19331982); pp. 237-238.

Bibliografía del P. Jesús Víctor San Román; pp. 239-240.

RUMRRILL, Róger. Jesús, una llamarada que se apaga en la Amazonía; pp. 241-244.

GARCÍA SÁNCHEZ, Joaquín. Tres viajes para una despedida; pp. 245-249.

DOUROJEANNI, Marc J. Bosques amazónicos: ecología y desarrollo rural; pp. 251-267.

REGAN, Jaime. La plebe y la aristocracia: autogestión en las fiestas populares de la selva; pp. 269-281.

GASCHE, Jürg, Alberto CHIRIF y José LÓPEZ PARODI. Alienación y resistencia: Reflexiones sobre una alternativa de desarrollo amazónico nativo; pp. 283-312.

PONTONI, Alberto. Políticas petroleras del Perú de 1980 a 1982; pp. 313-327.

GARCÍA SÁNCHEZ, Joaquín. Hacía una interpretación de la historia de las misiones en América Latina; pp. 329-349.

CHIRIF, Alberto. Masacre en Uchuracay: Mucho más que ocho muertes; pp. 351-366. 
Índice general de Shupihui: Revista Latinoamericana de Actualidad y Análisis (19761990)

ARROYO, José María. Panorama de la poesía en la selva; pp. 367-374.

MOREY ALEJO, Humberto. La serpiente interminable: siete canciones a Jesús San Román que amó a la Amazonía; pp. 375-386.

CALVO CÁNEPA, Igor. 2 narraciones breves: Pregúntenle a Orestes Apagüeño y Deca; pp. 387-391.

VÁSQUEZ IZQUIERDO, Jaime. El doctor Cáceres; pp. 393-398.

SAN ROMÁN, Jesús V. Problemas de la Amazonía: Criterios, objetivos y estrategias que deberán orientar la acción gubernamental y privada frente a los mismos; pp. 399-416.

\section{Volumen VIII. Número 25-26, enero-junio, Extraordina- rio, 1983 \\ Centroamérica escenario de pretensiones hegemónicas}

SHUPIHUI. Presentación; pp. 5-6.

1. TEMAS

INSTITUTO HISTÓRICO CENTROAMERICANO. Centroamérica escenario de pretensiones hegemónicas; pp. $440 \quad 9-51$.

IEPALA. Honduras, enclave estratégico; pp. 53-63.

Martirio y lucha en Guatemala, testimonio de la comunidad de La Estancia (El Quiche); pp. 65-79.

CABESTRERO, Teófilo. La iglesia católica en revolución; pp. 81-103. 


\section{DOCUMENTOS}

Comunicado oficial de la Dirección Nacional del FSLN sobre la religión; pp. 107-114.

Documento de la Conferencia Episcopal de Nicaragua; pp. 115-134.

Respuesta de los religiosos al documento del episcopado; pp. 135-143.

Carta de teólogos mexicanos a Juan Pablo II; pp. 144-166.

Síntesis de la ponencia de un documento de Ricardo Falla sobre el genocidio del gobierno de Ríos Montt; pp. 167-175.

Carta de los PP. Dominicos a Juan Pablo II; pp. 176-179.

Mensaje de Juan Pablo II en Centroamérica (Selección de textos); pp. 180-188.

\section{TEXTOS Y GLOSAS}

¿La religión contra la revolución?; pp. 191-199.

Juan Pablo II en Nicaragua; pp. 200-226.

4. AL RITMO DE LA NOTICIA; pp. 227-238.

5. BIBLIOGRAFÍA

Eguren, Fernando y otros. Situación actual y perspectivas del problema agrario en el Perú. DESCO, 1982; p. 241.

Collier, Richard. Jaque al barón. La historia del caucho en la Amazonía. CAAAP. Lima 1981; pp. 241-242. 
Índice general de Shupihui: Revista Latinoamericana de Actualidad y Análisis (19761990)

Grompone, Romeo, Mario Zolezzi y otros. La Lima de los 80. Crecimiento y segregación social. DESCO 1983; p. 242.

Parodi Z., Carlos y Fernando Gonzales Vigil. Empresas transnacionales, Estado y burguesía nativa. Publicaciones DESCO, 1983; p. 242.

Georg, Thomas. Política indigenista dos portugueses, Brasil (1500-1640). Ediciones Loyola. São Paulo 1982; p. 243.

Aramburu, C.; Bedoya, E. y Recharte. Colonización amazónica. CIPA. Impreso en Offset. Lima, 1982; pp. 243-244.

Muratorio, Blanca. Etnicidad, evangelización y protesta en el Ecuador. Centro de Investigaciones y Estudios Socio-Económicos. Primera edición, 1982; p. 244.

\section{Volumen VIII, Número 27, julio-setiembre 1983 Despertar de los pueblos indígenas en América Latina}

SHUPIHUI. Presentación; pp. 249-250.

\section{TEMAS}

Chile; pp. 253-264.

Argentina; pp. 265-270.

Paraguay; pp. 271-278.

Bolivia; pp. 279-289.

Perú; pp. 291-302.

Ecuador; pp. 303-306.

Brasil; pp. 307-312. 
Colombia; pp. 313-315.

Venezuela; pp. 317-330.

Panamá; pp. 331-338.

Costa Rica; pp. 339-348.

Nicaragua; pp. 349-366.

Guatemala; pp. 367-377.

México; pp. 379-385.

\section{DOCUMENTOS}

Consulta Ecuménica de Pastoral Indigenista Latinoamericana. Documento final; pp. 389-404.

\section{Volumen VIII, Número 28, octubre-diciembre 1983 III Coloquio sobre la Nueva Conquista de la Selva}

Presentación; pp. 409-410.

\section{TEMAS}

MOORE, Thomas. Situación de los nativos frente a la minería aurífera en Madre de Dios; pp. 413-426.

HEREDIA, Walter. Actualidad de la penetración en la Selva central, pp. 427-435.

YÉPEZ, Ernesto. El poblador ribereño de la Amazonía peruana; pp. 437-449.

LIRIO, José. Situación actual de las comunidades nativas del alto Marańón; pp. 451-466. 
Índice general de Shupihui: Revista Latinoamericana de Actualidad y Análisis (19761990)

BELLIER, Irene. Mai Huna y sociedad regional: penetración capitalista y transformaciones resultantes; pp. 467-491.

OCAMPO, Esteban. Política fiscal y descapitalización de la Amazonía peruana; pp. 493-510.

EQUIPO MISIONERO. La comunidad wangurina-napuruna del alto Napo; pp. 511-519

EQUIPO CAAAP-Iquitos. Actividad pesquera en la región. Participación campesina y nativa; pp. 521-528.

\section{TEXTOS Y GLOSAS}

REMY, María Isabel. Migrantes andinos a los lavaderos de oro de Madre de Dios; pp. 531-537.

DE IZCUE, Nora. El cine y su responsabilidad con la Amazonía; pp. 538-542.

TAMARIZ, María Eugenia. Avance de las fronteras de penetración en la selva ecuatoriana; pp. 543-549.

BROSEGHINI, Silvio. La colonización del territorio shuar. Actitudes que suscitó en los nativos y en los misioneros; pp. 550-556.

RUMRRILL, Róger. Difícil pero reveladora travesía hacia la $444 \quad$ tierra sin

CAUFIELD, Catherine. Represar el Amazonas, adelante a todo dar; pp. 564-577.

Madurez en el proceso. III Coloquio sobre la Nueva Conquista de la Selva; pp. 578-579. 
3. AL RITMO DE LA NOTICIA; pp. 581-590.

4. BIBLIOGRAFÍA

Regan, Jaime. Hacia la tierra sin mal. Estudio de la religión del pueblo en la Amazonía. CETA. Iquitos, 1983; p. 593.

Nimuendaju, Curt. Textos indigenistas. Ediciones Loyola. São Paulo, 1982; p. 594.

Fontanele De Carvalho, José Porfirio. Waimiri Atroari. La historia que todavía no fue contada. Brasilia 1982; p. 594.

Marzal, S.J., Manuel. Historia de la antropología indigenista: México y Perú. Pontificia Universidad Católica del Perú. Fondo Editorial, 1981; p. 595.

Tarrel, Gilda y Sara Da Ros. El acceso a la tierra del campesino ecuatoriano. Mundo Andino (Fundación Ecuatoriana Populorum Progressio) 1983; p. 595.

El Papa en Nicaragua. Análisis de su visita. Madrid, 1983; p. 596.

Volumen IX, Número 29, enero-marzo 1984 Sondeo de las fuentes históricas para un conocimiento objetivo del pasado de la Amazonía

SHUPIHUI. Presentación; pp. 5-6.

\section{TEMAS}

GARCÍA SÁNCHEZ, Joaquín. Proyecto de edición monumental de las fuentes históricas de la Amazonía; pp. 9-13.

PORRAS BARRENECHEA, Raúl. Esquema para una bibliografía amazónica; pp. 15-23. 
Índice general de Shupihui: Revista Latinoamericana de Actualidad y Análisis (19761990)

LEVISTRE DE RUIZ, Jeanine. Introducción a la historiografía de la Amazonía peruana; pp. 25-49.

VAN DEN BERG, Hans. Historiografía del oriente Boliviano: logros y tareas; pp. 51-69.

LEVISTRE DE RUIZ, Jeanine. Visión bibliográfica de los países amazónicos; pp. 71-111.

\section{DOCUMENTOS}

Mensaje al pueblo de Nicaragua en el Día Mundial de la Paz; pp. 115-118.

Encuentro Misionero Claretiano del Caribe y la Amazonía; pp. 119-129.

Lima: Encuentro Indigenista; pp. 130-132.

\section{TEXTOS Y GLOSAS}

De nuevo los matses en la noticia; pp. 135-136.

En defensa de la vida humana; pp. 137-139.

Marzal Guaraní: Líder y mártir de la causa del indio en la Amazonía; pp. 140-143.

Llueve sobre mojado; pp. 144-146.

4. AL RITMO DE LA NOTICIA; pp. 147-154.

\section{BIBLIOGRAFÍA}

Traducción de Silveri, Gentiloni. La sangre del justo. Testimonio martirial en América Latina. Edita Cittadella Editrice, Assisi 1983; p. 157. 
Cabestrero, Teófilo. Revolucionarios por el evangelio. Editorial Desclée de Brower S.A. Bilbao 1983; pp. 157-158.

Zarzar, Román. Relaciones intertribales en el bajo Urubamba y alto Ucayali. Edición CIPA; pp. 158-159.

Lima, una metrópoli: 7 debates. Edita: DESCO Centro de Estudios y Promoción del Desarrollo 1983; p. 159.

Verdera, Francisco. Notas sobre población, recursos y empleo en la selva peruana. Edita: Centro de Investigación Amazónica. Documento 4. Editora Andrómeda Dic 1982; p. 159-160.

Marzal, Manuel. La transformación religiosa peruana. Edita: Pontificia Universidad Católica del Perú. Fondo Editorial 1983; p. 160.

Volumen IX, Número 30, abril-junio 1984 Bilingüismo y educación bilingüe en las minorías indígenas amazónicas: fracasos y expectativas

SHUPIHUI. Presentación; pp. 165-166.

\section{TEMAS}

CORBERA MORI, Ángel. Idioma, etno-historias y educación bilingüe en las naciones de la Amazonía; pp. 169-178.

FRANCIS, Augusto. El pueblo amuesha y la educación bilingüe; pp. 179-182.

SAN ROMÁN, Gloria. Programa de educación bilingüe e intercultural del alto Napo; pp. 183-192. 
Índice general de Shupihui: Revista Latinoamericana de Actualidad y Análisis (19761990)

AMADIO, Massimo. Diagnóstico sobre la educación bilingüe en los distritos del Pastaza y Cahuapanas, provincia del alto Amazonas (Perú); pp. 193-212.

HEISE, María. Proyecto de educación bilingüe bicultural para los ashaninka del río Tambo; pp. 213-219.

TAVARES, Daniel. La realidad de la educación bilingüe en el departamento de Loreto; pp. 221-222.

TANG, Aurelio. Normas sobre educación bilingüe y su aplicación en el departamento de Loreto; pp. 223-230.

POZZI-ESCOT, Inés. Política educativa para poblaciones de habla vernácula; pp. 231-238.

TRAPNELL, Lucy. Mucho más que una educación bilingüe; pp. 239-246.

Programa de educación bilingüe en la sierra; pp. 247-250.

\section{DOCUMENTOS}

Carta a la Conferencia Episcopal del Perú; pp. 253-256.

Promoción turística y organización nativa; pp. 257-267.

\section{TEXTOS Y GLOSAS}

448 Apreciaciones del equipo del alto Napo respecto a la educación bilingüe e intercultural; pp. 271-276.

RAHNER, Karl. Carta póstuma del P. Karl Rahner sobre la teología de la liberación; p. 277-279.

Teología de la liberación, liberación de la teología; pp. 279281. 
Ante la Asamblea Episcopal; pp. 281-283.

Ataque a misión católica: Río Ene; pp. 284-285.

Proyecto editorial Monumenta Amazónica; pp. 285-288.

4. AL RITMO DE LA NOTICIA; pp. 289-302.

\section{BIBLIOGRAFÍA}

Díaz De Paula, Eunice y Luis Gouvea de Paula. Historia de los pueblos indígenas (medio siglo de lucha en el Brasil). Edita: Editorial Vozes Ltda., en coedición con el Consejo Indigenista Misionero CIMI. Petrópolis (Brasil) 1982; p. 305.

Cabestrero, Teófilo. Revolucionarios por el evangelio. Testimonio de 15 cristianos en el gobierno de Nicaragua. Edita: Desclée de Brower S.A., Bilbao 1983; pp. 305-306.

Cabrera Mori, Ángel. Bibliografía de la familia lingüística jíbaro. Edita: Universidad Nacional Mayor de San Marcos (Centro de Investigación Aplicada). Enero 1984; p. 306.

Informe socioeconómico del caserío Manacamiri. Edita: Dirección Regional de Agricultura. Dirección de Reforma Agraria y Asentamiento Rural. Iquitos, marzo de 1983; p. 307.

Chaumeil, Jean-Pierre. Ver, saber, poder. El chamanismo en los yaguas del noroeste Peruano. Ediciones de la Escuela de Estudios Superiores de Ciencias Sociales de París. 1983 (Francia) (en francés); p. 307.

El Cambio. Boletín Regional. Edita: CIMI (Coordinación y Secretaria) N. ${ }^{\circ}$ 1, julio 1983. Manaus; p. 308. 
Índice general de Shupihui: Revista Latinoamericana de Actualidad y Análisis (19761990)

Revolución nacional e identidad indígena. El conflicto entre los sandinistas y los indios miskitos en la costa atlántica de Nicaragua. Edita: Klaudine Ohland y Robin Schneider. Copenhague, noviembre 1983; p. 308.

Plan Nacional de Desarrollo de Loreto. Edita: Oficina Regional de Planificación de Loreto. Año 1983-1984; p. 308.

Plan Nacional de Desarrollo de Loreto. Edita: Oficina Regional de Planificación de Loreto. Año 1983-1984. 2a. parte; p. 309 .

Díaz de Paula, Eunice, Luis Gouvea de Paula y Elizabeth Aracy Rondon Amarante. Confederación de los Tamolos. Edita: Vozes y CIMES. Petrópolis 1984; p. 310.

Tierra y vida. Semana del indio. 1984. Edita: CNBB y CIMI; p. 310 .

Volumen IX, Número 31-32, julio-diciembre 1984 Teología de la liberación en la teología de la misión: Encuentro fecundo de dos corrientes de la Iglesia

SHUPIHUI. Presentación; pp. 316-318.

\section{TEMAS}

GARCÍA SÁNCHEZ, Joaquín. Corta pero intensa historia; pp. 323-327.

GUTIÉRREZ, Gustavo. De la teología de la misión a la teología del encuentro; pp. 329-337.

SUESS, Paulo. Den testimonio de su esperanza (1 Ped. 3,15); diálogo y misión; pp. 339-350. 
ELIZONDO, Virgilio. El idioma de la resistencia, la supervivencia y la liberación; pp. 351-362.

\section{DOCUMENTOS}

Documentos oficiales de la iglesia; pp. 365-375.

Documentos de los episcopados de América Latina; pp. 376388.

Otros documentos de pastoral de base; pp. 388-393.

\section{TEXTOS Y GLOSAS}

Experiencias misioneras en América Latina (1970-1984); pp. 397-440.

Teología de la liberación en África; pp. 441-446.

4. AL RITMO DE LA NOTICIA; pp. 447-458.

\section{BIBLIOGRAFÍA}

Chango, Alfonso. Yachaj Sami Yachachina. Ediciones: AbyaYala, Quito Ecuador. Colección Mundo Shuar, 1984; p. 461.

Rueda, Marco V., Recopilador Tankamash R. Setenta mitos shuar. Editorial: Mundo Shuar 1983; pp. 461-462.

Beksta, Casimiro. 1a. Cartilha tukano. Edita: SEDUC, Manaus 1984; p. 462.

Amazonía peruana. Edita: CAAAP Lima; p. 462.

Población indígena y desarrollo amazónico. Edita: Ministerio de Bienestar Social. Oficina Nacional de Asuntos Indígenas. Editora Abya-Yala, Quito 1984; p. 463. 
Índice general de Shupihui: Revista Latinoamericana de Actualidad y Análisis (19761990)

Bernales, Enrique. El parlamento por dentro. Edita: DESCO. Lima 1984; p. 463.

Eguiguren, Francisco y Javier Neves. Alternativa de los trabajadores ante el cierre de las empresas. Edita: DESCO (Centro de Estudios y Promoción del Desarrollo) 1984; p. 464.

Cabrera, Segundo y equipo de relatores. El tío lobo y el sobrino conejo (Nawpac Parlucuna). Edita: Abya-Yala Quito 1984. Colección Nukanchic Unancha; p. 464.

Bazán Blas, Fidel y Enrique Ballón Aguirre. Aprendiendo a conocer los problemas ecológicos y el manejo de las tierras en ceja de selva. CIPA. (Centro de Investigación y Promoción Amazónica); p. 464.

Aco Cataldo, Raúl. Diagnostico general del estudio e investigación científica y tecnológica en la Amazonía peruana. Iquitos, 1982; p. 465.

Moscoso, Roque y Carlos Yáñez B. Colonización. El encuentro de dos culturas. Edita: CIPA (Centro de Investigación y Promoción Amazónica) Mayo 1984; p. 465.

Cuji, Aurelio. Qué es lo que hace nuestra gente. Cerámica festiva (Runa) Sarayacu. Cerámica quichua. Fotografías del Museo de Artesanía y Misión Carmelita. Quito; p. 466.

452 Carrasco, Eulalia. El pueblo chachi. El jeengume avanza. Colección Ethnos, 1983; pp. 466-467.

Costales, Alfredo y Piedad. Amazonía. Ecuador-Perú-Bolivia. Edita: Mundo Shuar 1983 (Ecuador); pp. 467-468.

Ortiz, Dionisio. Pucallpa y el Ucayali, ayer y hoy. Edita: Apostolado de la Prensa S.A. Lima-1984; p.468. 
Volumen X, Número 33, enero-marzo 1985

Discurso misionero de Juan Pablo II: el viaje del Papa por la América india

SHUPIHUI. Presentación; pp. 5-6.

\section{DOCUMENTOS}

GARCÍA SÁNCHEZ, Joaquín. El pensamiento misionero de Juan Pablo II en sus mensajes a los indígenas; pp. 9-21.

Mensaje de Juan Pablo II a los indígenas de la Amazonía; pp. 22-23.

Discurso del Papa a los amerindios e inuit (esquimales) en Santa Ana de Beaupré, 10 de setiembre. El encuentro con el evangelio; pp. 24-30.

Juan Pablo II en Santa María de los Hurones; pp. 31-36.

Discurso a los indígenas en el aeropuerto de Latacunga, 31 de enero. Hombres de todas las razas y culturas unidos según la voluntad de Dios en una sola comunidad de amor, en una inmensa familia cuya cabeza es Jesucristo; pp. 37-44.

Solidaridad, hospitalidad; pp. 45-54.

La voz de una asamblea histórica; pp. 55-56.

Tayta Papata Chaskina Shimikuna; pp. 57-61.

Encuentro con la Amazonía; pp. 62-72.

OBISPOS DEL PERÚ. Documento de la Conferencia Episcopal Peruana sobre la teología de la liberación; pp. 73-96. 
Índice general de Shupihui: Revista Latinoamericana de Actualidad y Análisis (19761990)

\section{TEXTOS Y GLOSAS}

Primera muestra internacional de cine sobre ecología, recursos naturales y conservación; pp. 99-101.

GARCÍA SÁNCHEZ, Joaquín. Iquitos: Fiesta de pueblos indígenas; pp. 102-106.

4. AL RITMO DE LA NOTICIA; pp. 107-118.

\section{BIBLIOGRAFÍA}

Iglesias, pueblos y culturas N. ${ }^{\circ}$ 2. Quito, Ediciones AbyaLaya 1985; p. 121.

Webb, R. y otros. El cristiano ante el Perú de 1985: crisis económica, violencia. Lima, Centro de Proyección Cristiana, 1984; p. 121.

Ottolenghi, Aldo. Culturas prehistóricas. Buenos Aires. Eds. Plus Ultra 1984; p. 122.

Marzal, Manuel M. El sincretismo iberoamericano. Lima, Fondo Editorial, 1985; p. 122.

Quedena, E. y A. Villavicencio. Manual del poblador. Lima. DESCO, 1984; p. 123.

454 Lima. DESCO, 1985; pp. 123-124.

Gutarra Maraví, Eleazar. La cordillera del Cóndor. Lima, 1984; p. 124.

Brasil ¿Para quién es la tierra? Lima, CEP, 1984; p. 124.

Alba Herrera C., Augusto. Atusparia y la revolución campesina de 1885 en Áncash. Lima, Ed. Alfa, 1985; p. 125. 
Aguilo, Federico. El hombre de Chimborazo. Eds. AbyaYala, 1985; p. 125.

Coba Andrade, Carlos. Danzas y bailes en el Ecuador. Ediciones Abya-Yala, Ecuador, 1985; p. 126.

Shaffer, Frederick W. Motivos indígenas del antiguo Ecuador. Quito. Eds. Abya-Yala, 1985; pp. 126-127.

Obando A., Segundo. Cuadernos de cultura popular. Eds. Abya-Yala, 1984/5. Colección Nucanchic Unancha; p. 126.

Ayarza U., Armando y Bendayan D. Teddy. Bubinzana. Literatura mágica de la Amazonía. 1985. Lima Talleres Gráficos de Martegraf; p. 127.

\section{Volumen X, Número 34, abril-junio 1985 El presente y el futuro de la salud en la Amazonía}

SHUPIHUI. Presentación; pp. 134-135.

\section{TEMAS}

FORT, Alfredo. Políticas y programas de salud: del dicho al hecho...; pp. 137-143.

FORT, Alfredo. "Centralismo" y salud en Iquitos; pp. 145-149.

GARCÍA MARTÍNEZ, Edward. Situación epidemiológica de la salud de la población del departamento de Loreto; pp. 151-171.

RAMOS FILHO, Celso F., Paulo F. ALMEIDA LÓPES y Fernando S. VIANA MARTINS. Problemática actual de la malaria; pp. 173-184. 
Índice general de Shupihui: Revista Latinoamericana de Actualidad y Análisis (19761990)

COLÁN BERNAL, Ernesto. La lepra en Iquitos: mitos y realidades; pp. 185-187.

RAMÍREZ GARCÍA, Juan J. Problemática de la salud oral en la Amazonía: alternativa de solución; pp. 189-192.

MOURA GARCÍA, Julia. Perfil de los promotores de salud; pp. 193-198.

SOUCY MARTÍN, Gaetana. Promotores de salud - Proyección hacia el futuro en la Amazonía peruana; pp. 199-204.

VILLAR NARREA, Daniel. El CAAAP: Proyectos de salud; pp. 205-208.

GÓMEZ RUMICHE, Félix. Testimonio de un médico rural en la Amazonía; pp. 209-211.

RAMÍREZ DEL RISCO, Eduardo. Plan cívico fluvial de la Amazonía Peruana; pp. 213-216.

\section{DOCUMENTOS}

URRUTIA, Carlos, Ana BOGGIO y Alejandrino MAGUINA. La enfermedad capitalista de la salud popular; pp. 219234.

\section{TEXTOS Y GLOSAS}

456 Salud y campesinado en el Sur Andino; pp. 237-244.

Antropología médica y medicina folklórica en la Amazonía Peruana; pp. 245-252.

Etnomedicina de la Amazonía; pp. 253-259.

SABATIER, R. C. El SIDA: ¿Otra enfermedad “tercermundista"?; pp. 260-261. 
La curandera de Oaxaca; pp. 261-262.

4. AL RITMO DE LA NOTICIA; pp. 263-276.

\section{BIBLIOGRAFÍA}

White, Alan. Hierbas del Ecuador. Plantas medicinales. Quito, Eds. Libri Mundi. 1985. 3ra. edición; p. 279.

Palma africana y etnocidio. Quito, Edita CEDIS-CONFENIAE, 1985; p. 279.

Acero Coral, Gloria y Pianalto, M. A. Medicina indígena. Cacha-Chimborazo. Quito, Mundo Andino, 1985; p. 280.

Veneno para el desayuno. El peligro de los pesticidas en la agricultura. Quito, Eds. Abya-Yala y CESAP, 1985; p. 280.

\section{Volumen X, Número 35-36, julio-diciembre 1985}

Situación actual de la mujer en la Amazonía y en el Perú

SHUPIHUI. Presentación; pp. 285-286.

1.- TEMAS

BARCLAY, Frederica. Para civilizarlas mejor. Reflexiones acerca de programas de desarrollo para mujeres en sociedades amazónicas; pp. 289-300.

DRADI, María Pía. Masculino-femenino: entre el equilibrio y la subordinación (El caso de la sociedad chayahuita); pp. 303-322.

SALICK, Jan. Subsistencia y mujeres solas entre los Amuesha; pp. 323-334. 
Índice general de Shupihui: Revista Latinoamericana de Actualidad y Análisis (19761990)

ANDERSON, Jeanine. Los sistemas de género y el desarrollo de la selva; pp. 335-345.

LORA, Carmen y Cecilia BARNECHEA. Reflexiones sobre sexualidad e identidad de la mujer; pp. 347-372.

ROSELLO, Fuencisla. Dos testimonios: Rigoberta Menchú y Domitila Chungara; pp. 373-381.

CAMINO, Lupe. Testimonio de una campesina piurana: "unidos tenemos que empezar a unirnos"; pp. 383-387.

LÓPEZ DE SORIA, Eloísa. Reflexiones de una mujer: la mujer en la iglesia; pp. 389-394.

\section{2.- DOCUMENTOS}

Documento de la Organización de Agustinos de Latinoamérica (OALA); pp. 397-404.

Carta del Cardenal Evaristo Arns a Fidel Castro, a propósito de la deuda externa; pp. 405-407.

\section{3.- TEXTOS Y GLOSAS}

Mujer, sexualidad y población; pp. 411-414.

La década de la mujer: Aún queda lo más difícil; pp. 415416.

Las empleadas domésticas se organizan: Perú; pp. 416-417.

Arraigado abuso sexual sufren latinoamericanas; pp. 418423.

Museo de la humanidad de Londres. Realidad amazónica tergiversada; pp. 423-427. 
4.- AL RITMO DE LA NOTICIA; pp. 429-444.

5.- BIBIOGRAFÍA

Publicaciones relacionadas con la problemática de la mujer amazónica; pp. 447-448.

Volumen XI, Número 37, enero-marzo 1986 Dinámica poblacional en la Amazonía del Perú

SHUPIHUI. Introducción; pp. 5-6.

1. TEMAS

RODRÍGUEZ ACHUNG, Martha. Poblamiento de la Amazonía desde el siglo XIX hasta 1940; pp. 7-28.

CAENAZZO, Mara. La población de Pucallpa; pp. 29-72.

MARTÍNEZ, Héctor. Jenaro Herrera: una experiencia de colonización en la selva baja peruana; pp. 73-96.

RODRÍGUEZ DE GUTIÉRREZ, Martha. El crecimiento urbano de Iquitos: condicionamientos estructurales en la década del 70; pp. 97-104.

\section{DOCUMENTOS}

Tenencia de la tierra y proceso social en la Amazonía ecuatoriana; p. 107-125.

La tierra: don de Dios - derecho del pueblo; pp. 126-142. 
Índice general de Shupihui: Revista Latinoamericana de Actualidad y Análisis (19761990)

\section{TEXTOS Y GLOSAS}

Reacciones de iglesias y líderes religiosos a la ayuda norteamericana a los contrarrevolucionarios nicaragüenses; pp. 143-150.

Terra e vida: los indios en Brasil; pp. 150-152.

Esclavos del caucho; pp. 152-154.

4. AL RITMO DE LA NOTICIA; pp. 155-164.

\section{BIBLIOGRAFÍA}

Comblin, José. Tiempo de acción. Edita Centro de Estudios Teológicos de la Amazonía - CETA y Centro de Estudios y Publicaciones - CEP. Lima, 1986; p. 165.

Gutiérrez, Gustavo. La fuerza histórica de los pobres. Ediciones CEP (Centro de Estudios y Publicaciones). 2a . ed., Lima, 1980; p. 165.

Gutiérrez, Gustavo. Beber en su propio pozo, en el itinerario espiritual de un pueblo. Eds. CEP. Lima 1983; p. 166.

Gutiérrez, Gustavo. Hablar de Dios desde el sufrimiento del inocente. Una reflexión sobre el libro de Job. Editan Instituto Bartolomé de las Casas - CEP. Lima 1986; p. 166.

460 Gutiérrez, Gustavo. La verdad os hará libres. Editan Instituto Bartolomé de las Casas -CEP. Lima 1986; p. 166.

Gutiérrez, Gustavo; Luis Idígoras y otros. Reflexión sobre la teología de la liberación. Perspectivas desde el Perú. Eds. CETA. Iquitos, 1986; p. 167.

Sánchez I., Manuel. Pensamientos breves sobre las bienaventuranzas. Eds. CEP. Lima 1985; p. 167. 
Espeja, Jesús. Espiritualidad y liberación. Edición CEP. Lima 1986; p. 167.

Crespo, Luis Fernando. Vocación cristiana y tarea de los jóvenes. Eds. CEP. Lima 1986; p. 168.

Tovar, Teresa. Velasquismo y movimiento popular. Otra historia prohibida. Eds. DESCO. Lima 1985; p. 168.

Zevallos Chávez, Humberto. Una puerta que perdimos. Edita Róger Rumrrill. Lima 1986; p. 168.

\section{Volumen XI, Número 38, abril-junio 1986 Proyecto Monumenta Amazónica}

Introducción; pp. 175-176.

\section{TEMAS}

CHIRIF, Alberto. Monumenta Amazónica: fundamentos y organización de la obra; p. 177-183.

Proyecto Monumenta Amazónica; pp. 185-220.

\section{TEXTOS Y GLOSAS}

COURTNEY, Maureen. Datos sobre la historia y la cultura de la costa Atlántica de Nicaragua; pp. 221-242.

Informativo Campaña Javari; pp. 242-246.

Informe del Consejo Indio de Suramérica preocupa a la Santa Sede; pp. 247-254.

La confederación de nacionalidades indígenas de la Amazonía ecuatoriana denuncia ante la opinión pública nacional e 
Índice general de Shupihui: Revista Latinoamericana de Actualidad y Análisis (19761990)

internacional que el gobierno prepara nueva intromisión del Instituto Lingüístico de Verano al país; pp. 254-265.

\section{Volumen XI, Número 39-40, julio-diciembre 1986 Pueblos indígenas de América}

SHUPIHUI. Introducción; pp. 271-272.

\section{TEMAS}

Población indígena de América Latina: tres tentativas de estadísticas; pp. 273-294.

Tenencia de la tierra en América Latina y su repercusión sobre los pueblos indígenas; pp. 295-300.

GARCÍA SÁNCHEZ, Joaquín. Hambre de Dios, hambre de pan, hambre de la tierra: una aproximación al problema indígena; pp. 301-312.

Argentina: Cultura Toba; pp. 313-321.

ALBÓ, Xavier. Bolivia: El sinuoso camino de la historia y de la conciencia hacia la identidad nacional aymara; pp. 323353.

RIVERO P., Wigberto. Bolivia: Situación indígena en la región Amazónica y alternativas de desarrollo; pp. 355-363.

Brasil: Projeto Calha Norte; pp. 365-370.

Brasil: Política indigenista oficial; pp. 371-377.

SUESS, Paulo. Chile: Autodeterminación para el pueblo Mapuche; pp. 379-382. 
Colombia: La cuestión indígena, Consejo Regional Indígena del Cauca (CRIC) Colombia; pp. 383-385.

PROAÑO V., Leónidas E. Ecuador: Situación actual de los indígenas en el Ecuador; pp. 387-395.

Guatemala: Documento del Movimiento popular guatemalteco a la II Consulta Ecuménica; pp. 397-415

México: Pueblos indígenas de México; pp. 417-456.

Perú: Organizaciones nativas en la Amazonía Peruana; pp. 457-460.

CABARRÚS S. J., Carlos. Panamá: El pueblo kuna de Panamá; pp. 461-470.

Paraguay: Situación de los pueblos indígenas de Paraguay; pp. 471-476.

\section{DOCUMENTOS}

El renacer de amerindia; pp. 477-478.

II Consulta Ecuménica de Pastoral Indigenista. Quito; pp. 479-483.

Manifiesto indígena contra las celebraciones del V Centenario del Descubrimiento y de la Primera Evangelización en América; pp. 484-485.

Confederación de nacionalidades indígenas de la Amazonía ecuatoriana; pp. 486-497.

Declaración ecuménica. Jornada de Intercambio MapuchePastoral; pp. 498-500. 
Índice general de Shupihui: Revista Latinoamericana de Actualidad y Análisis (19761990)

\section{TEXTOS Y GLOSAS}

Declaración de Indiana; pp. 501-502.

El Rimanacuy de Pucallpa: balance y perspectivas; pp. 502511.

Intervención de Melillán Painemal en la II Asamblea Ecuménica (Quito-Ecuador); pp. 511-516.

Voces indígenas; pp. 517-520.

Apuntes de historia; pp. 520-531.

Desde el silencio indio (fragmentos); pp. 532-536.

\section{BIBLIOGRAFÍA}

Morete Solari, Fernando. Marxismo. Crítica al materialismo dialéctico. 1986; p. 537.

San Agustín. Confesiones. Edita: CETA Iquitos, Perú, 1986: p. 538 .

Boff, Clodovis. San Agustín de Hipona y la pastoral de la liberación. Edita: Centro de Estudios Teológicos de la Amazonía (CETA), Iquitos. Perú. 1984; p. 538.

Educación popular y estrategia de cambio. Edita: III Jorna464 das Latinoamericanas del Consejo de Cultura celebradas en Lima. Lima 1986; p. 538.

Volumen XII, Número 41, enero-marzo 1987 Cultura, cosmovisión y problemática indígenas en América Latina

Introducción; pp. 5-6. 
ALBÓ, Xavier. Culturas y cosmovisión andina; pp. 9-28.

TAMARIZ T., María Eugenia. Situación actual de los pueblos indios de la Amazonía: un breve acercamiento; pp. 2944.

Situación actual de los pueblos indios amazónicos (trabajo de grupos); pp. 45-63.

ALBÓ, Xavier. Una nación con 40 naciones; pp. 65-83.

REGAN, Jaime. Religión indígena amazónica; pp. 85-90.

SEUSS, Paulo. Alteridad, integración, resistencia: apuntes sobre liberación y la causa indígena; pp. 91-113.

PANTELIS M., Jorge. El ministerio laico en América Latina; pp. 115-121.

Situación actual del ministerio laico en los países andinos; pp.123-128.

\section{DOCUMENTOS}

Sembrar la vida para cosechar la paz; pp. 129-134.

\section{TEXTOS Y GLOSAS}

Lineamientos para una pastoral nativa en la Amazonía peruana; pp. 135-139.

Por la vida que es la libertad; pp. 139-149.

El Alto Andagueda; pp. 150-158.

Paraguay: Indígenas mueren en cacería de hombres; pp. 158163. 
Índice general de Shupihui: Revista Latinoamericana de Actualidad y Análisis (19761990)

Campaña amazónica "Preservar la Amazonía”: sumarios y resultados; pp. 164-168.

Represas amenazan el Xingu; pp. 168-172.

Conferencia Episcopal Peruana; pp. 173-175.

AL RITMO DE LA NOTICIA; pp. 177-186. BIBLIOGRAFÍA

Cultura amazónica. Revista. Iquitos, I.N.C., 1987; p. 187.

García Sánchez, Joaquín. El río que se aleja. Cambio del curso del Amazonas. Historia y estudio técnico. Iquitos, CETA, 1987; p. 187.

Buenaventura, Pelegrini. Intelectuales cristianos en el mundo de hoy. Lima, CEP, 1987; p. 188.

Pahua, Diego. La informalidad popular y cambio social. Lima, DESCO, 1987; p. 188.

Desarrollo a escala humana; una opción para el futuro. CPAVR y Fundación Da Nammerbajold; p. 188.

Iglesia, Pueblos y Culturas (Revista). Quito, Eds. Abya-Yala, 1987; p. 189.

466 Polani, Jacques. San Juan de Lurigancho, su historia y su gente. Lima, CEP, 1987; p. 189.

Soucy, Gaetana. Manual para promotores en salud. Iquitos, CETA, 1987. 5ta. ed.; p. 190.

Trigo, Pedro. Cristianismo e historia en la novela mexicana contemporánea. Lima, CEP, 1987; p. 190. 
Zevallos, Noe. Comentario al Cántico del Hermano Sol. Lima, CEP, 1987; p. 190.

\section{Volumen XII, Número 42-44, abril-diciembre 1987 La Región del Amazonas. Los políticos amazónicos se pronuncian}

Introducción; pp. 195-197.

\section{TEMAS}

PULGAR VIDAL, Javier. La regionalización transversal del Perú; pp. 199-225.

PINEDO NÁJAR, Juan. La región del Amazonas. Sugerencias estratégicas para su implementación y desarrollo; pp. 227-243.

PANDURO CORAL, Moisés. La región del Amazonas: Un logro revolucionario; pp. 245-271.

BARLETTI PASCUALE, José. Algunas reflexiones sobre regionalización, descentralización y democracia; pp. 273-282.

VALERA SUÁREZ, Rony. La eterna sombra del centralismo; pp. 283-295.

SICCHAR VALDEZ, José. Proyecto aprista destinado al fracaso; pp. 297-302.

PEREIRA RÍOS, Raúl. Proceso de regionalización. Posición del Partido Popular Cristiano (PPC); pp. 303-306.

ALVÁN DEL CASTILLO, José Silfo. Una propuesta regionalista; pp. 307-310. 
Índice general de Shupihui: Revista Latinoamericana de Actualidad y Análisis (19761990)

\section{DOCUMENTOS}

Ley orgánica de la región del Amazonas; pp. 311-316.

\section{TEXTOS Y GLOSAS}

SANTOS, Fernando. Los rostros de la Amazonía; pp. $317-$ 320.

ÁLVAREZ, José. Ecología de la región del Amazonas; pp. 321-329.

GARCÍA ANGULO, Genaro. La cuestión económica de la región del Amazonas; pp. 330-334.

GARCÍA, Joaquín. Algunos levantamientos regionalistas de la historia de Loreto, pp. 334-336.

\section{AL RITMO DE LA NOTICIA; pp. 337-356. \\ BIBLIOGRAFÍA}

Castonguay, Luis. Nuestra fe católica. Iquitos, Vicariato San José del Amazonas, 1987; p. 357.

Foletti-Castegnaro, Alessandra. Cantos de amor y de guerra: ¡Aguaricu Shayari!. Quito, Eds. Abya-Yala, 1987; p. 357.

Hundelson, Jhon Edwin. La cultura quichua de transición.

468 Quito, Eds. Abya-Yala, 1987; p. 358.

Ibarra, Alicia. Los indígenas y el Estado en el Ecuador. Quito, Eds. Abya-Yala, 1987; p. 359.

Laur, Pedro. Cerca del corazón del pueblo. Iquitos, CETA, 1987; p. 359. 
Rahier, Jean. La décima: poesía oral negra del Ecuador. Quito, Eds. Abya-Yala, 1987; p. 360.

Whitten, Norman E. Sacha Runa. Etnicidad y adaptación de los quichua hablantes de la Amazonía ecuatoriana. Quito, Eds. Abya-Yala, 1987; p. 361.

\section{Volumen XIII, Número 45-46, enero-junio 1988 La música en la Amazonía. 1. Etnomúsica}

Introducción; pp. 5-6.

\section{TEMAS}

PINILLA, Enrique. La música de la selva peruana; pp. 9-35.

CHAUMEIL, Jean Pierre. Las fiestas: abandono y supervivencia; pp. 37-46.

RESPALDIZA ROJAS, José y Luis SALAZAR ORSI. Palo zumbador: un juguete infantil prehistórico de uso vigente en el Perú; pp. 47-65.

STOCKS, Anthony. Tendiendo un puente entre el cielo y la tierra en alas de la canción; pp. 67-98.

MERCIER, Juan Marcos. Napuruna uyachisa takina: música napu; pp. 99-102.

SANTOS GRANERO, Fernando. Cantos del espíritu: misticismo indígena en los trópicos sudamericanos; pp. 103-122.

CHIRIF TIRADO, Alberto, Stefano VARESE y Josafat ROEL. Voces e instrumentos de la selva: aguaruna-campa; pp. 123-136. 
Índice general de Shupihui: Revista Latinoamericana de Actualidad y Análisis (19761990)

BELLIER, Irene. Los cantos Mai Huma del yajé (Amazonía peruana); pp. 137-154.

CIPOLLETI, María Susana. El animalito doméstico quedó hecho cenizas. Aspectos del lenguaje shamánico secoya; pp. 155-175.

SHERZER, Joel. El arte verbal de los cantos shamanísticos cuna; pp. 177-1986.

ADAMS, Patsy. Textos culina; pp. 187-194.

DOCUMENTOS

Reflexiones de la iglesia de Pucallpa sobre violencia; pp. 195203.

La misión de los laicos en la construcción de la paz; pp. 205217.

\section{TEXTOS Y GLOSAS}

MENDOZA, Vicente T. Música precolombina en América; pp. 219-241.

RUMRRILL, Róger. La magia de la música y la danza indígenas; pp. 242.

470

GUALLART, José María. Poemas extraídos de: Poesía lírica aguaruna; pp. 243-246.

Instrumentos musicales de la selva del Perú; pp. 247-282.

AL RITMO DE LA NOTICIA; pp. 283-300. 


\section{BIBLIOGRAFÍA}

Amazonía Peruana N. ${ }^{\circ} 15$ (Revista). Lima, CAAAP, 1988; p. 301 .

Campodónico, H. et al. Situación y perspectivas de la minería del cobre. Lima, DESCO, 1988; pp. 301-302.

Durand, Francisco. La burguesía peruana: Los primeros industriales. Alan García y los empresarios. Lima, DESCO, 1988; p. 302.

Pennano, Guido. La economía del caucho. Iquitos, Eds. CETA, 1988; pp. 302-303.

Quedena, E. P. Iturregui, D. Palma y M. Zolezzi. Derecho, promoción social y sectores populares urbanos. Lima, DESCO, 1988; p. 303.

Villarejo, Avencio. Así es la selva. Iquitos, Eds. CETA, 1988, 4ta. edición 330 p.; p. 304.

Zegarra, A. et. al. Caminando juntos (preparación a la confirmación). Lima, Ed. CEP. 217 p; p. 304.

\section{Volumen XIII, Número 47-48, julio-diciembre 1988}

La música en la Amazonía. 2. Música popular en la selva del Perú

Introducción; pp. 311-312.

TEMAS

SALAZAR ORSI, Luis. Intento de aproximación a la música amazónica; pp. 315-321. 
Índice general de Shupihui: Revista Latinoamericana de Actualidad y Análisis (19761990)

IZQUIERDO RÍOS, Francisco. Breve historia de la música en la selva; pp. 323-333.

El cancionero popular de la región; pp. 335-415.

SALAZAR ORSI, Luis. Apuntes para el estudio de algunos temas clásicos de la música popular amazónica; pp. 417-425.

Panorama de la música riojana actual; pp. 427-443.

DOCUMENTOS

La salvación integral del indígena, hoy es Jesucristo; pp. 445448.

OBISPOS DEL PERÚ. Dos importantes documentos de los obispos peruanos; pp. 449-459.

TEXTOS Y GLOSAS

WONG, Antonio y Jorge RUNCIMAN. Bajo el sol de Loreto (vals serenata); pp. 461-462.

DE PINA Y PEÑA, Julio C. El trabajo y el estudio (ronda rítmica); pp. 463-464.

SALAZAR ORSI, Luis. Bravo Marino (vals). Transcripción y arreglo para guitarra; p. 465.

472 GARCÍA, J. y R. Vásquez. Canción triste al navegante; pp. 466-474.

Ficha de registro de autores, compositores, músicos y obras musicales de la Amazonía peruana; pp. 475-478.

AL RITMO DE LA NOTICIA; pp. 479-496. 


\section{BIBLIOGRAFÍA}

Cipolleti, M. S. Alpé Koka. La palabra de los antiguos. Quito, Eds. Abya-Yala y MLAL, 1988; p.497.

Fuentes, A. Porque las piedras no mueren. Historia, sociedad y ritos de los chayahuitas del alto Amazonas. Lima, CAAAP, 1988; pp. 497-498.

Hulshof, José. Economía política del sistema de salud. Lima, DESCO, UNMSM, 1988; p.498.

Karsten, R. La vida y la cultura de los shuar. Editan AbyaYala y Banca Central del Ecuador (Quito 1988), t. I. 292 pp.; p. 499.

Renard Casevitz, F. M. y otros. Al este de los Andes. Quito, Eds. Abya-Yala y MLAL, 1988; p. 500.

Telban, B. Grupos étnicos de la Colombia. Etnografía y bibliografía. Editan Ediciones Abya-Yala y MLALA (Movimiento Laico para América Latina) (Quito 1988) 526 pp.; p. 500 .

Varios autores. I Seminario de Investigaciones Sociales de la Amazonía. Iquitos, CETA, 1988; pp. 500-501.

Volumen XIV, Número 49-52, enero-diciembre 1990 Comunidades cristianas en la Amazonía: 20 años de historia. Homenaje al P. Antonio Aladro García

GARCÍA SÁNCHEZ, J. Introducción; pp. 7-11. 
Índice general de Shupihui: Revista Latinoamericana de Actualidad y Análisis (19761990)

\section{TEMAS}

LAUR, Pedro. Presencia de la comunidad cristiana en la vida del caserío; pp. 13-30.

HARVEY, Gastón. Plan de formación de los animadores; pp. $31-43$.

LOZANO, Víctor. El animador, ¿líder alternativo en su comunidad?; pp. 45-56.

CARBALLO, Jesús. Movimiento de comunidades cristianas y animadores de comunidad; pp. 57-66.

MARTIN, Juan Luis. Los animadores de comunidades cristianas: una mirada al futuro; pp. 67-70.

FUERTES, Miguel. Las comunidades cristianas: generadoras, dadoras y defensoras de la vida; pp. 71-73.

\section{TEXTOS Y GLOSAS}

FLORES AMPUERO, Jesús Dionisio. Testimonio de mi vida de "animación misionera"; pp. 75-77.

SANCHEZ MACEDO, Juan Benito. Mi historia de animador de comunidad; pp. 78-81.

474 cia; pp. 81-82.

TORRES MOZOMBITE, Rolando. Sufrimos, pero la verdad triunfa; pp. 83-85.

Entrevista a Jaime Bernuy; pp. 86-88.

SORIA MELÉNDEZ, Luis. Mi experiencia como animador de comunidad cristiana; p. 88-90. 
Testimonio de Santa Clotilde; pp. 90-92.

Testimonio de los animadores de Nauta; pp. 93-97.

HARVEY, Gastón. Ministerio laical de "misionero"; pp. 9899.

LAUR, Pedro. Acompañando a mi pueblo; pp. 100-104.

CENCCA: La concreción de un sueño; pp. 105-115.

\section{BIBLIOGRAFÍA}

Michelena y Rojas, Francisco. Exploración oficial por la primera vez desde el norte de América del Sur siempre por ríos... Iquitos, IIAP-CETA 1989; p. 117.

Biedma, Manuel y otros. La conquista franciscana del alto Ucayali. Iquitos, IIAP-CETA, 1982; p. 117.

Barclay, Frederica. La colonia del Perené. Serie Debate. Iquitos, CETA, 1989; p. 118.

Amazonía Peruana. CAAAP. Vol. IX, N.o 17 julio 1989; p. 118.

Gutiérrez, Gustavo. El Dios de la vida. Editado por el Centro de Estudios y Publicaciones (CEP), Lima 1989. 368 pp.; p. 118

\section{Agradecimientos}

Al padre Joaquín García Sánchez OSA, ex director del Centro de Estudios Teológicos de la Amazonía (CETA); a la licenciada Rosa Alejandra Schindler Catalao, ex directora de la Biblioteca Amazónica y al Sr. Julio Ramírez Arévalo, actual coordinador de la Biblioteca Amazónica del Vicariato Apostólico de Iquitos. 
Índice general de Shupihui: Revista Latinoamericana de Actualidad y Análisis (19761990)

Recibido:09 de diciembre del 2020

Aprobado:18 de abril del 2021

\section{Referencias bibliográficas}

Centro de Estudios Teológicos de la Amazonía (CETA).

(1981) Shupihui nueva etapa. Shupihui, VI (17), 5-6.

(1998) Revistas. Kanatari 15(700), 70-71.

(2004) Base de datos. Kanatari 1000 [CD-Rom]. Iquitos. 